\title{
Geologia e ocorrências de ouro do Terreno Granito-Greenstone do Tocantins, TO: síntese do conhecimento e parâmetros para exploração mineral
}

\author{
Raul Minas Kuyumjian', Emílio Lenine Carvalho Catunda da Cruz², \\ José Oswaldo de Araújo Filho ${ }^{3}$, Marcia Abrahão Moura ${ }^{4}$, Edi Mendes Guimarães ${ }^{4}$ \& \\ Karla Munique da Silva Pereira ${ }^{5}$
}

\begin{abstract}
Resumo O Terreno Granito-Greenstone do Tocantins é composto por domos granito-gnáissicos e estreitas faixas de greenstone, formados em ambiente de subducção no Paleoproterozoico. As ocorrências de ouro nesse terreno são hospedadas em quartzo de veios associados a produtos de alteração hidrotermal de anfibolito, formação ferrífera bandada e rochas graníticas em zonas de cisalhamento. Sugere-se que as ocorrências e depósitos de ouro do Terreno Granito-Greenstone do Tocantins formaram-se durante a orogênese Brasiliana, com a participação de fluidos hidrotermais de origem metamórfica, com contribuição granítica. Os dados obtidos até o presente revelam critérios de exploração mineral para ouro no Terreno Granito-Greenstone do Tocantins.
\end{abstract}

Palavras-chave: Tocantins, greenstone, ouro, exploração mineral.

\begin{abstract}
Geology of and gold occurrences in the Granite-Greenstone Terrane of Tocantins, Central Brazil: state of the art and guide lines for mineral exploration programs. The Paleoproterozoic Tocantins GraniteGreenstone Terrane is composed of granite-gneissic domes and narrow intervening greenstone belts. Tholeiitic metabasalts and calc-alkaline metatonalites have chemical composition characteristic of subduction tectonic environment. The main gold concentrations occur in iron-rich amphibolite, banded iron formation and granitic rocks. It is suggested that the Tocantins Granite-Greenstone Terrane gold occurrences and deposits were formed by dominantly metamorphic hydrothermal fluids during the Brasiliano Orogeny, with granitic contribution. Guide lines for mineral exploration programs for gold in the Tocantins Granite-Greenstone Terrane are presented.
\end{abstract}

Keywords: Tocantins, greenstone, gold, exploration guide lines.

INTRODUÇÃO O Terreno Granito-Greenstone do Tocantins (TGGT) faz parte do embasamento do extremo norte da zona externa da Faixa Brasília, Província Tocantins. A atual cartografia geológica do TGGT é produto de levantamentos realizados na porção centro-norte do terreno (Nilson \& Valle 1973, Costa et al. 1976, Correia Filho \& Sá 1980, Costa 1984, Cruz 1993, Cruz \& Kuyumjian 1998) e sul (Padilha 1984, Kuyumjian \& Araujo Filho 2005). Borges (1993) e Cruz \& Kuyumjian (1998) definiram, respectivamente, modelo de evolução tectono-estrutural e fases de deformação da porção norte do TGGT, enquanto Arthaud (1988) descreveu feições estruturais da porção sul. As primeiras descrições mais detalhadas de ocorrências de ouro do TGGT são de autoria de Costa et al. (1976) e Correia Filho \& Sá (1980). Alteração hidrotermal (Silva et al. 1990, Cruz \& Kuyumjian 1999), controle estrutural (Cruz 2001, Ferrary \& Choudhuri 2004), dados geocronológicos, geotermobarométricos e isotópicos (Cruz \& Kuyumjian 2006) e inclusões fluidas (Ferrari \& Choudhuri 2004) do depósito Córrego Paiol embasaram sugestões relativas à mineralização de ouro no TGGT (Cruz \& Kuyumjian 2006). O presente trabalho apresenta uma síntese do conhecimento em relação às ocorrências de ouro do TGGT e resultados de estudo preliminar em inclusões fluidas de veios de quartzo auríferos encaixados em anfibolito, formação ferrífera e biotita granito. Os dados obtidos revelam critérios de exploração mineral para ouro no TGGT.

\section{CONTEXTO GEOLÓGICO DO TGGT O TGGT} compreende estreitas faixas de greenstone contornando domos elipsoidais constituídos de gnaisses tonalíticos (Fig. 1). A sequência do greenstone constitui o Grupo Riachão do Ouro, que compreende metabasaltos e metaultrabásica da Formação Córrego Paiol,

1 - Departamento de Geoquímica e Recursos Minerais, Instituto de Geociências, Universidade de Brasília, Brasília (DF), Brasil. E-mail: raulmk@unb.br

2 - Instituto Nacional de Criminalística, Departamento de Polícia Federal, Brasília (DF), Brasil. E-mail: elccc@uol.com.br

3 - Departamento de Geologia Geral e Aplicada, Instituto de Geociências, Universidade de Brasília, Brasília (DF), Brasil. E-mail: oswaldo@unb.br

4 - Departamento de Mineralogia e Petrologia, Instituto de Geociências, Universidade de Brasília, Brasília (DF), Brasil. E-mail: mamoura@unb.br, rxedi@unb.br

5 - PETROBRAS, Rio de Janeiro (RJ), Brasil. E-mail: karlamuniq@gmail.com 


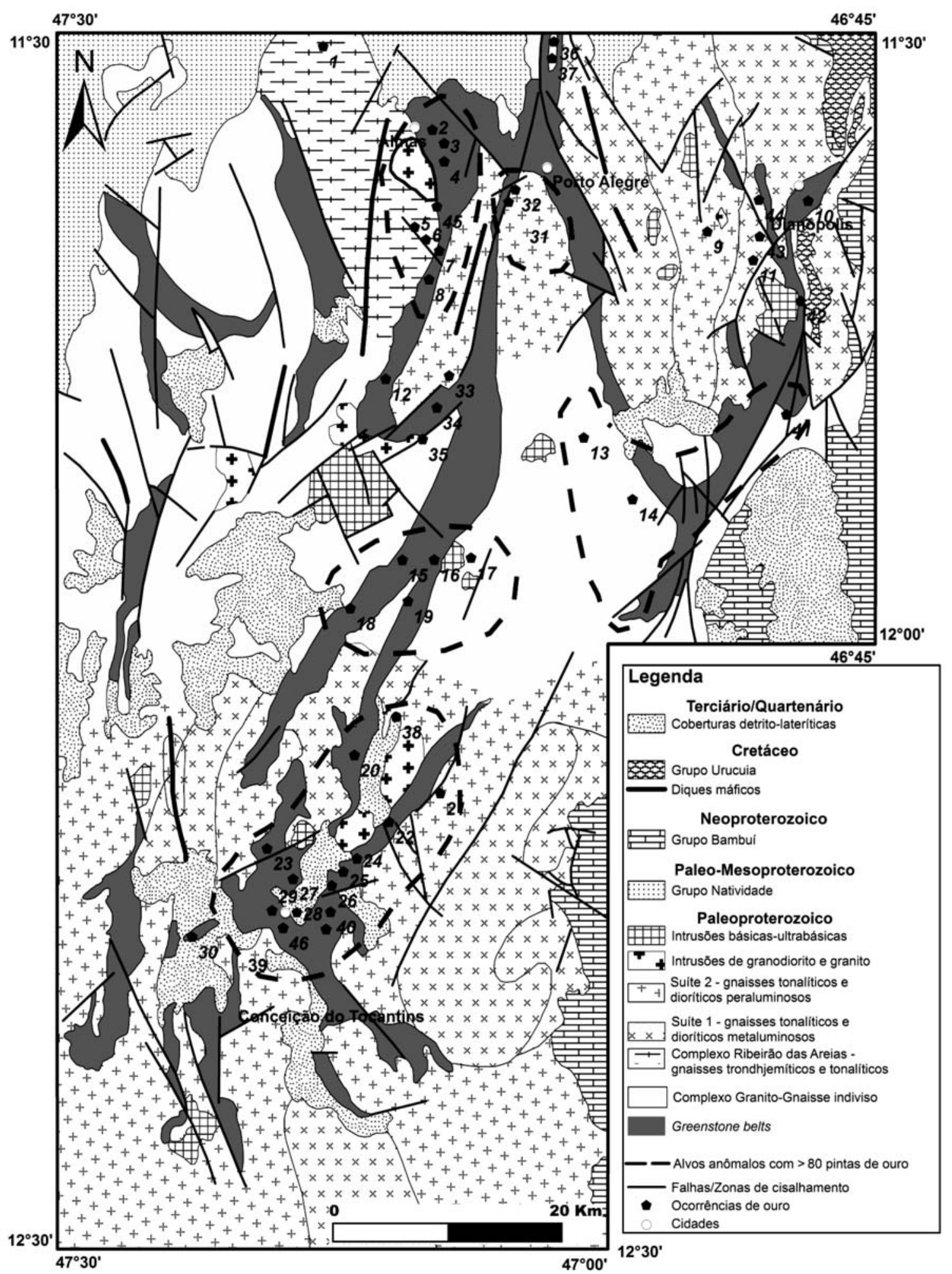

Figura 1 - Geologia e ocorrências e depósitos de ouro do Terreno Granito-Greenstone do Tocantins (Costa et al. 1976, Padilha 1984, Cruz \& Kuyumjian 1999, Kuyumjian \& Araújo Filho 2005). 1 Córrego Recantinho, 2 - Arroz, 3 - Refresco, 4 - Vieira, 5 - Vira-Saia I, 6 - Vira -Saia II, 7 - Olavo, 8 - Mina Córrego Paiol, 9 - Faz. Santo Elias, 10 - Tapuias, 11- Jacú, 12 - Urubú, 13 - Lagartixa, 14 - Terra Vermelha, 15 - Faz. Curral Queimado, 16 e 17 - Faz. Santaninha, 18 - Faz. Poço de Ouro, 19 - Faz. Misericórdia, 20 - Cangalha/ Santo Amaro, 21 - São Filipe, 22 - Tuna, 23 - Furtuosa, 24 - Piçarrão, 25 - Faz. Elegante / Riachão, 26 - Córrego Gavião, 27 - Maria Pinta, 28 - Gerseu, 29 - Igrejinha, 30 - Cajazeira, 31 - Córrego Lopes, 32 - Seriema, 33 - Nova Prata, 34 - Espinheiro, 35 - Boa Nova, 36 - Garrafas, 37 - Tamanduá, 38 - Lagoa do Ouro, 39 - Jatai, 40 - Faz. Nova, 41 Sucupira, 42 - Lavrinha, 43 - Buzina, 44 - Altamira, 45 - Faz. Sucuriú, 46 - Aeroporto Conceição. 
sobrepostos por filito sericítico carbonoso, quartzito, metassilexito, xisto carbonoso, formação ferrífera bandada, metaconglomerado e, subordinadamente, rochas metavulcânicas félsica (muscovita-plagioclásio-quartzo xisto), intermediária (clorita-anfibólio xisto feldspático) e máfica (anfibólio xisto e anfibolito) da Formação Morro do Carneiro (Costa et al. 1976, Correia Filho \& Sá 1980, Costa 1984, Padilha 1984, Cruz \& Kuyumjian 1998). Nos domos ocorrem intrusões paleoproterozoicas de granodioritos, granitos e corpos máfico-ultramáficos constituídos de gabro, piroxenito, peridotito e dunito, além de diques $\mathrm{N} 30^{\circ} \mathrm{W}$ de diabásio, provavelmente do Cretáceo. Coberturas alúvio-coluvionar arenosa, produto de intemperismo principalmente de arenitos cretácicos do Grupo Urucuia, e laterítica são extensas no TGGT.

As faixas de greenstone distribuem-se em forma de Y (Fig. 1), de direção NS com ramificações para NE e NW (Costa et al. 1976, Cruz \& Kuyumjian 1998) e cuja origem deve-se, inicialmente, à forma dos domos, alojados como corpos elípticos alongados (Kuyumjian \& Araújo Filho 2005). Cruz \& Kuyumjian (1998) identificaram dois grupos principais de estruturas de deformação no TGGT. As mais antigas, pré-brasilianas, geradas no evento $\mathrm{D}_{1}$ decorrente do posicionamento dos domos, compreendem, no âmbito das faixas de greenstone, dobras verticais apertadas e xistosidade subvertical paralela ao contato entre os greenstone belts e os domos. Durante esse evento instalou-se uma tectônica transcorrente destral de direção NS, com transporte tectônico de SSW para NNE e com a partição da deformação em duas direções principais de cisalhamento, $\mathrm{N} 60^{\circ} \mathrm{E}$ e $\mathrm{N} 60^{\circ} \mathrm{W}$, subverticais. Zonas de cisalhamento direcionais $\mathrm{D}_{2}$ brasilianas, com movimentação destral, direção principal N20-40 $\mathrm{E}$ e subsidiárias N0$-10^{\circ} \mathrm{E}$ e $\mathrm{N} 10-30^{\circ} \mathrm{W}$, controlam a distribuição dos veios de quartzo hidrotermal (Kuyumjian \& Araújo Filho 2005). Zonas de cisalhamento $\mathrm{N} 35-50^{\circ} \mathrm{W}$ sinistrais e $\mathrm{N} 40-70^{\circ} \mathrm{E}$ destrais, resultantes de um regime distensivo posterior no interior de zonas de cisalhamento numa fase $\mathrm{D}_{3}$, afetam rochas do TGGT (Kuyumjian \& Araújo Filho 2005) e rochas metassedimentares da cobertura da zona externa da Faixa Brasília (Gorayeb et al. 1988), além de serem responsáveis por boudinagem de veios de quartzo e segregações de sílica auríferos (Cruz \& Kuyumjian 1999, Ferrari \& Choudhury 2000). Enxames de veios de quartzo rúpteis, localmente penteados, estéreis e truncados por juntas, podem ter se originado nessa fase de deformação.

Arthaud (1988) evidenciou duas fases de deformação na porção sul do TGGT: a primeira, de natureza dúctil, cisalhamento simples, provocou estiramento EW em seixos de quartzito conglomerático e dobramento mais evidente na formação ferrífera bandada; a segunda, de cisalhamento puro, provocou crenulação com plano axial subvertical de direção NS. Sigmoides em seixos de quartzito conglomerático registram transporte tectônico de SSW para NNE e de NW para SE. Segundo Kuyumjian \& Araújo Filho (2005), as faixas de greenstone na porção sul do TGGT, dispostas nas direções $\mathrm{N} 10-35^{\circ} \mathrm{E}, \mathrm{N} 45^{\circ} \mathrm{W}$ e $\mathrm{NS}$, mostram foliações miloníticas $\mathrm{N} 50-60^{\circ} \mathrm{E} / \mathrm{NW}, \mathrm{N} 20^{\circ} \mathrm{E} / 35 \mathrm{SW}$, $\mathrm{N} 50^{\circ} \mathrm{W} / 55^{\circ} \mathrm{SW}$ e EW $/ 45^{\circ} \mathrm{S}$, barras de quartzo com caimentos de $45^{\circ}$ a $65^{\circ}$ para SW e veios de quartzo nas direções $\mathrm{N} 40-60^{\circ} \mathrm{W}, \mathrm{N} 20^{\circ} \mathrm{E}, \mathrm{N} 40-60^{\circ} \mathrm{E}$ e NS, localmente boudinados.

Cruz \& Kuyumjian $(1998,1999)$ reconheceram dois eventos metamórficos no TGGT: o primeiro (M1), associado ao evento $\mathrm{D}_{1}$, é restrito aos greenstone belts, enquanto o segundo (M2), relacionado às zonas de cisalhamento $\mathrm{D}_{2}$, afeta todas as unidades do TGGT. Nos metabasaltos, as paragêneses metamórficas variam da fácies anfibolito à fácies xisto verde, para as quais se obtiveram $576 \pm 46$ a $632 \pm 60^{\circ} \mathrm{C}$ e $3,9 \pm 2$ a $4,4 \pm 2,3$ kbars para a fácies anfibolito, $485 \pm 18$ a $539 \pm 65^{\circ} \mathrm{C}$ e $4,0 \pm 0,2$ a 4,4 $\pm 0,5$ kbars para a fácies epidoto anfibolito e 320 a $400^{\circ} \mathrm{C}$ e 2 kbar para a fácies xisto verde.

\section{LITOQUÍMICA E AMBIENTE GEOTECTÔNICO}

Segundo, respectivamente, Silva et al. (1990) e Ferrari \& Choudhuri (2000), os metabasaltos da Formação Córrego Paiol apresentam afinidades químicas com basaltos de arco de ilhas e basaltos de rifte continental. Cruz (1993) e Cruz \& Kuyumjian (1996) identificaram dois grupos de metabasaltos na região Almas-Dianópolis: 1) de alto ferro, com $[\mathrm{Mg} /(\mathrm{Mg}+\mathrm{Fe})]_{\text {mol }}=0,46-0,62, \mathrm{TiO}_{2}=$ $0,64-1,10 \%$ e características químicas de basaltos toleíticos originados em zona de subducção; e 2) de alto magnésio, almofadados, com $[\mathrm{Mg} /(\mathrm{Mg}+\mathrm{Fe})]_{\text {mol }}=0,60-0,82$, $\mathrm{TiO}_{2}=0,26-0,72 \%$, provavelmente komatiitos extrudidos em ambientes de rifte ou bacia de retroarco continentais. Metatonalito e metadiorito do TGGT apresentam composições químicas características de ambiente de subducção, sendo que os da suíte 1, metaluminosos, derivaram, provavelmente, da fusão parcial de manto tipo mantle wedge, enquanto os da suíte 2 , peraluminosos, resultaram de fusão parcial de metabasaltos de litosfera oceânica subductada (Thomsen \& Kuyumjian 1994b, Cruz \& Kuyumjian 1998, Cruz et al. 2003). Segundo Thomsen \& Kuyumjian (1994a), a formação ferrífera bandada da região de Conceição do Tocantins apresenta composição química semelhante à obtida por Graf (1978) para formações ferríferas paleoproterozoicas. Metagabro intrusivo em metatonalito na porção sul do TGGT apresenta composição química (Cruz 1993) semelhante à obtida por Thompson et al. (1984) e Beard (1986) para rochas de magmatismo básico em ambiente de colisão continental. 
IDADES Idades Rb-Sr de $2050 \pm 276$ e $2217 \pm 85 \mathrm{Ma}$ em rocha total obtidas por Costa (1984) em metatonalito dos domos foram interpretadas como resultantes de rejuvenescimento isotópico. Cruz \& Kuyumjian (1999) obtiveram idades Sm-Nd de 2,53 Ga para metatonalitos da Suíte 1 e 2,50-2,52 Ga para os da suíte 2, enquanto Cruz et al. (2003) obtiveram idades U-Pb de 2,2 e $2,45 \mathrm{Ga}$ em zircão e titanita de tonalitos, respectivamente, meta e peraluminosos. Tais idades e a presença de xenólitos de xistos máficos das rochas supracrustais nos metatonalitos e de apófises e veios destes nas rochas supracrustais indicam que os corpos tonalíticos se alojaram nos greenstone belts no Paleoproterozoico. Dardenne et al. (2009) obtiveram idade $\mathrm{U}-\mathrm{Pb}$ de $2206 \pm 13 \mathrm{Ma}$ em zircão de rocha metavulcânica ácida a intermediária da Formação Morro do Carneiro. Diques de riodacito sericitizado e de idade Sm-Nd de 2,58 Ga cortam o anfibolito hospedeiro do depósito Córrego Paiol (Cruz \& Kuyumjian 2006). Segundo Fuck et al. (2010), tonalitos que ocorrem em Conceição do Tocantins apresentam idades U-Pb obtidas em zircão $\operatorname{com} 2,3 \mathrm{Ga}$

\section{OCORRÊNCIAS E DEPÓSITOS DE OURO NO TGGT}

Breve histórico As atividades de exploração de ouro no TGGT remontam a 1734 e 1741, desenvolvidas, respectivamente, por portugueses na região de Almas e pelo bandeirante Manoel Paes de Andrade no município de Conceição do Tocantins. Em 1840, desbravadores vindos do Vale do São Francisco iniciaram a explotação de ouro na mina Tapuias, em Dianópolis. Em 1920, o português Bernardo Homem dedica-se à explotação de ouro na região de Almas, empregando mão de obra escrava e indígena. Nas décadas de 1980 e 1990 predominou a atividade garimpeira.

Programas de exploração mineral para ouro foram desenvolvidos no TGGT a partir de 1976: prospecção em sedimentos de drenagens e solos efetuada pela DOCEGEO-METAGO (1977-1989), detectando-se anomalias com $>80$ pintas de ouro (Fig. 1); sondagens no depósito Córrego Paiol, tendo sido cubada reserva de 3,4 t Au de minério oxidado a um teor de $1,53 \mathrm{~g} / \mathrm{t}$ (Kwitko et al. 1995) e de 1,6 Mt a 3,9 g/t Au para o depósito primário (DOCEGEO 1995); e prospecção em sedimentos de drenagem executada pela CPRM no âmbito de rochas máficas e ultramáficas do Morro da Gameleira (Lima 2000). No período de 1996 a 2000, a VALE produziu 86.000 onças de ouro supergênico na cava a céu aberto do depósito Córrego Paiol e, em 2001, suspende suas atividades no depósito devido à baixa cotação do ouro no mercado internacional. Programas de exploração mineral no TGGT têm incluído sensoriamento remoto multiespectral para contrastar zonas de alteração hidrotermal e confirmar correlação entre óxidos e hidróxidos de ferro com ouro no depósito Córrego Paiol (Ferrari et al. 1998), aeromagnetometria para evidenciar lineamentos estruturais e camadas de formação ferrífera bandada e gamaespectrometria para evidenciar zonas de potassificação e polarização induzida em anfibolitos com alteração hidrotermal e grãos de sulfetos disseminados. Em 2010, a Rio Novo Gold Inc. estimou, para o depósito Paiol, reserva total de 5 milhões toneladas a $2,26 \mathrm{~g} / \mathrm{ton}$.

Segundo Cruz (1993), a evolução metamórfico-deformacional do TGGT é semelhante à de gold-only provinces, enquanto Kwitko et al. (1995) e Cruz \& Kuyumjian (1999) classificaram as ocorrências de ouro presentes no mesmo como mesotermal do tipo lode, de média temperatura. A mineralização de ouro se deu pela percolação de fluidos hidrotermais em zonas de cisalhamento do tipo transcorrente destral no evento dúctil-rúptil $\mathrm{D}_{2}$ (Cruz \& Kuyumjian 1998), durante retrometamorfismo das rochas do TGGT, da fácies anfibolito para a fácies xisto verde (Ferrari \& Choudhuri 2004). As principais ocorrências e depósitos de ouro no TGGT (Fig. 1) são hospedadas por formação ferrífera bandada, anfibolito rico em ferro e rochas graníticas dos domos (Cruz 2001, Cruz \& Kuyumjian 1999) que, da mesma forma que a maioria dos depósitos e ocorrências de ouro do Maciço de Goiás e da Faixa Brasília (Araújo Filho \& Kuyumjian 2000), são controladas por zonas de cisalhamento. Várias ocorrências de ouro, por exemplo, Seriema, Nova Prata, Santo Amaro, Altamira, Buzina, Serra da Porteira, São Felix, Fazenda Planalto e Lavrinha, distribuem-se ao longo de zonas de cisalhamento $\mathrm{D}_{2}$ coincidentes com contatos tectônicos entre domos e faixas de greenstone.

Valores de $\delta^{34} \mathrm{~S}_{(\mathrm{CDT})}$ entre $1,83 \%$ e $2,12 \%$ em pirita do minério do depósito Córrego Paiol não permitiram discriminar nenhum tipo de reservatório preferencial para o enxofre (Cruz 2001), enquanto valores entre $1,9 \%$ e $1,3 \%$, obtidos por Ferrari \& Choudhuri (2004) em pirita e calcopirita foram interpretados como indicativos de fonte magmática para o enxofre. Dados geotermobarométricos, isotópicos de $\mathrm{Pb}$ em pirita, de $\mathrm{C}$ e $\mathrm{O}$ em anquerita, e idades $\mathrm{Ar}^{40}-\mathrm{Ar}^{39}$ obtidas em clorita e muscovita hidrotermais do depósito indicam que o mesmo originou-se há $563 \pm 15 \mathrm{Ma}$, durante o resfriamento que se seguiu a uma fase de descompressão relacionada a uma trajetória P-T-t horária desenvolvida na fase final da orogênese Brasiliana (Cruz 2001, Cruz \& Kuyumjian 2006). Segundo Dávila \& Kuyumjian (2005), as ocorrências de ouro hospedadas por rochas da sequência vulcano-sedimentar paleoproterozoica das regiões de São Domingos (GO) e Correntina (BA), localizadas próximas ao TGGT, também teriam se formado durante a orogênese Brasiliana. 
Ocorrências de ouro em anfibolito O anfibolito rico em ferro da Formação Córrego Paiol hospeda o depósito Córrego Paiol e várias ocorrências de ouro, entre elas, Olavo, Arroz, Refresco, Juí, Tapuias, Quincas, Vieira, Getúlio e Buzina, associadas a zonas de cisalhamento $\mathrm{N} 10-30^{\circ} \mathrm{E}$ e N20-40 $\mathrm{W}$ (Fig. 1). O anfibolito do depósito foi submetido à carbonatação, sericitização, silicificação, sulfetação e, subordinadamente, albitização, cloritização, turmalinização e epidotização, em zona de cisalhamento destral $\mathrm{N} 20^{\circ} \mathrm{E} / 70^{\circ} \mathrm{NW}$ (Cruz 2001), na intersecção com zona de cisalhamento NS (Kwitko et al. 1995) e na intersecção da foliação milonítica penetrativa $\mathrm{S}_{\mathrm{n}+1}$ com falhas extensionais $\mathrm{S}_{\mathrm{n}+2}$ (Ferrari \& Choudhuri 2000, 2004). Os sulfetos constituem pirita, arsenopirita, pirrotita e calcopirita, sendo que as maiores concentrações de ouro ocorrem em zonas de alteração hidrotermal onde predominam clorita, sericita, albita, anquerita e pirita (Silva et al. 1990), quartzo, anquerita, albita, pirita, mica branca e rutilo, principalmente onde piritização é intensa (Cruz \& Kuyumjian 1999, Cruz 2001) e zona de intensa silicificação do anfibolito e do metagabro (Ferrari \& Choudhuri 2004). As concentrações de ouro apresentam aumento progressivo da rocha encaixante em direção aos estágios mais avançados da alteração hidrotermal (Kwitko et al. 1995). O minério é, essencialmente, disseminado. As maiores concentrações de ouro no depósito do Arroz ocorrem em zonas de alteração hidrotermal com pirrotita.

Na ocorrência Tapuias, o ouro ocorre em veios de quartzo marrom-róseo encaixados em anfibolito e meta-andesito, nas proximidades de interseção de faixas de greenstone $\mathrm{N} 20^{\circ} \mathrm{W}$ e $\mathrm{N} 30^{\circ} \mathrm{E}$. Os veios de quartzo, com espessura de 0,30 a $1 \mathrm{~m}$, boudinados, apresentam direções $\mathrm{N} 80^{\circ} \mathrm{W}, \mathrm{N} 60^{\circ} \mathrm{E}$ e NS. Esses veios contêm turmalina, pirita e mica branca e são envelopados por material marrom-escuro pulverulento (óxido de ferro e sulfetos oxidados?), (turmalina-quartzo-biotita-) carbonato-clorita xisto, (quartzo-clorita-) sericita xisto e, mais externamente, carbonato-clorita-epidoto xisto com relictos de plagioclásio. Ouro, pirita, calcopirita e malaquita ocorrem em microfraturas no quartzo marrom-claro dos veios e no material marrom-escuro pulverulento. Nas ocorrências Arroz e Porteira, o ouro ocorre em quartzo leitoso e enfumaçado de veios $\mathrm{N} 30^{\circ} \mathrm{W} / 40^{\circ} \mathrm{SW}$, boudinados e encaixados em pirita-albita-sericita xisto orlado por quartzo-carbonato-clorita xisto e clorita-sericita-carbonato xisto (Teixeira et al. 1986).

Ocorrências de ouro em formação ferrífera bandada As ocorrências de ouro em formação ferrífera bandada e xisto que foram submetidos à alteração hidrotermal estão localizadas, principalmente, na região de Conceição do Tocantins, parte sul do TGGT (Cruz \& Kuyumjian 1999). Na ocorrência Gerseu, localizada na interseção de faixas de greenstone NE e NW, o ouro, associado à pirita, pirrotita, calcopirita, galena, esfalerita e bismutinita, ocorre em veios de quartzo de 30 a $80 \mathrm{~cm}$ de espessura, encaixados em formação ferrífera bandada silicificada, carbonatizada e brechada, e em veios e/ou segregações de quartzo branco leitoso presentes em xisto com foliação $\mathrm{N} 20^{\circ} \mathrm{W} / 35^{\circ} \mathrm{SW}$, encaixantes da formação ferrífera e constituído de sericita, carbonato, clorita, turmalina, biotita, magnetita, sulfeto, grunerita e cloritoide. Cloritito, actinolitito com turmalina e metassilexito com bolsões de carbonato+clorita estão presentes na zona de alteração hidrotermal. As principais concentrações de ouro e sulfetos ocorrem, aparentemente, no contacto entre a formação ferrífera e o xisto imediatamente encaixante. A presença de grãos euédricos de pirita na foliação desse xisto sugere que a mineralização foi contemporânea a metamorfismo. Veios centimétricos de carbonato+turmalina cortam a zona de alteração hidrotermal. Na ocorrência Cajazeira, o ouro ocorre em veios de quartzo+turmalina, encaixados em quartzo-clorita xisto e formação ferrífera bandada intercalados com metassilexito, jaspelito e xisto carbonoso com foliação $\mathrm{N} 60^{\circ} \mathrm{E}$, subvertical. Em testemunhos de sondagens, ocorrem intervalos de $30 \mathrm{~cm}$ de xisto carbonoso constituído de $80 \%$ de pirita+pirrotita, além de carbonato, biotita, actinolita, clorita e concentrações muito baixas de Au. Nas ocorrências Gerseu e Cajazeira, ocorrem barras e segregações de quartzo com sulfeto e, localmente, ouro, em zonas axiais de dobras fechadas e dobras isoclinais métricas.

Ocorrências de ouro em metatonalito, metagranodiorito e metagranito Nas ocorrências dos domos do TGGT, o ouro, na forma livre e/ou incluso em pirita, ocorre em veios de quartzo contendo turmalina, carbonato, sericita, clorita e sulfetos (Cruz \& Kuyumjian 1999). Em afloramento, os veios apresentam $20 \mathrm{~cm}$ a $4 \mathrm{~m}$ de espessura e 50 a $300 \mathrm{~m}$ de extensão, o quartzo é ora leitoso ora enfumaçado e a alteração hidrotermal associada é controlada por zonas de cisalhamento N50$-70^{\circ} \mathrm{W}$ (Pedra d'Ávila), N30 ${ }^{\circ} \mathrm{W}$ (Vira-Saia I), N50-70 ${ }^{\circ} \mathrm{E}$ (Vira-Saia II, Lagartixa e Misericórdia), N10 ${ }^{\circ} \mathrm{E}$ (Lavrinha e São Felipe), $\mathrm{N} 30^{\circ} \mathrm{E}$ (Terra Vermelha e Córrego Lopes) e NS (Garrafas).

Na ocorrência Vira-Saia II (ou do Baiano), a alteração hidrotermal de metatonalito originou veios de quartzo leitoso e enfumaçado ou quartzo-carbonato no centro, envelopados por zona de pirita-quartzo-sericita-albita e zona de sericita-albita-epidoto. Os veios são verticalizados e contêm pirita, arsenopirita, calcopirita e galena. Na ocorrência Vira-Saia I, veios de quartzo branco leitoso e enfumaçado são envelopados por zona de quartzo-sericita, zona de clorita e, mais externamente, epidoto metagranito. A ocorrência 
Santo Elias, localizada em interseção de falhas NE e

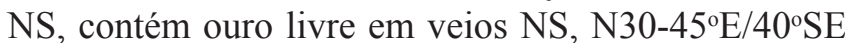
e $\mathrm{N} 70^{\circ} \mathrm{E} / 50^{\circ} \mathrm{SE}$, encaixados em biotita metagranito e constituídos de quartzo enfumaçado cataclástico, principal portador do ouro, pirita, arsenopirita, calcopirita e malaquita e cimentado por quartzo leitoso. Os veios, de 1 a $6 \mathrm{~m}$ de espessura, são envelopados por zona de material marrom pulverulento constituído de quartzo, hematita, goethita, esmectita e sepiolita; zona de alteração argílica constituída de caolinita, quartzo, illita, montmorilonita e albita; zona de carbonato-albita-quartzo-clorita e, mais externamente, metagranito com carbonato (Alvarez 2007). Na ocorrência Lavrinha, ouro, pirita, arsenopirita, malaquita e azurita ocorrem em zonas de estrangulamento de veio de quartzo enfumaçado cataclástico de direção $\mathrm{N} 10^{\circ} \mathrm{E}$, subvertical, boudinado e encaixado em metagranodiorito. Na ocorrência Terra Vermelha, o veio de quartzo leitoso aurífero é envelopado por zonas de caolinização e cloritização; na ocorrência Pedra d'Ávila, veio de quartzo $\mathrm{N} 50^{\circ} \mathrm{W}$ encaixado no granodiorito Garrafas contém arsenopirita e elevadas concentrações de ouro e cobre; nas ocorrências Tamanduá e Garrafas, ouro, sulfetos e turmalina ocorrem em zonas entre boudins de veio de quartzo enfumaçado de direção NS, encaixado em metagranodiorito. Na ocorrência Nova Prata-Espinheiro, veios de quartzo leitoso contendo ouro, pirita, calcopirita e malaquita são envelopados por quartzo-sericita xisto e encaixados em xisto feldspático caolinizado. Nas ocorrências Piçarrão, Lagoa do Ouro e São Felipe, ouro e pirita ocorrem em veios de quartzo enfumaçado encaixados em gnaisse granítico com foliação milonítica $\mathrm{N} 40^{\circ} \mathrm{E} / 35^{\circ} \mathrm{NW}$.

Ocorrências de ouro em outros tipos de rocha Ocorrências de ouro no TGGT são hospedadas também por rochas metavulcânicas ácida e intermediária, quartzito, metaconglomerado e filito sericítico carbonoso (Correia Filho \& Sá 1980, Cruz \& Kuyumjian 1999). Na fazenda Elegante, segregações e veios de quartzo contendo magnetita, carbonato, sulfeto e $\mathrm{Au}$ ocorrem em quartzo-clorita xisto feldspático (metatufo andesítico) com foliação milonítica $\mathrm{N} 40^{\circ} \mathrm{E} / 70^{\circ} \mathrm{NW}$. No garimpo do Urubú (Serra da Porteira), as principais concentrações de ouro ocorrem em zona de quartzo leitoso sacaroidal na forma de charuto NE, hospedado em sericita-quartzo-carbonato-clorita xisto (metatufo andesítico?), clorita-sericita quartzo xisto (metavulcânica ácida?) e magnetita-sericita quartzito (formação ferrífera?). Nas ocorrências Morro do Carneiro e Morro do Urubú, o ouro ocorre em, respectivamente, turmalina quartzito e metarenito argilo-ferruginoso, sendo que, na primeira, há correlação positiva entre concentração de ouro e abundância de turmalina. Nas ocorrências Vieira e Juí, pouco conhecidas, o ouro ocorre em porções carbonosas de filito sericítico.

Características químicas Cruz \& Kuyumjian (1999) e Kuyumjian \& Araújo Filho (2005) obtiveram valores de 3,38 ppm Au no depósito Vira-Saia II (metatonalito), de 2,50 a 54 ppm Au e até 100 ppm As na ocorrência Santo Elias (biotita granito) e de 0,56 a 27,5 ppm $\mathrm{Au}, 140$ ppm Zn, 900 ppm Cu, 90 ppm Ni, 132 ppm Sr, 2035 ppm Ba, 0,8 ppm Bi, 0,3 ppm Sb, 1,4 ppm Te e $8,1 \mathrm{ppm}$ Sc na ocorrência Gerseu (formação ferrífera bandada). A tabela 1 apresenta valores médios das concentrações de elementos traço do biotita-granito da ocorrência Santo Elias, anfibolito da ocorrência Tapuias, formação ferrífera da ocorrência Gerseu e de seus produtos de alteração hidrotermal e, na figura 2 , padrões de distribuição de elementos traço, potássio e enxofre das zonas de alteração hidrotermal.

Ítrio e zircônio foram menos mobilizados pelos processos de alteração hidrotermal das ocorrências Tapuias, Gerseu e Santo Elias. As concentrações mais elevadas de $\mathrm{Au}, \mathrm{As}, \mathrm{Pb}, \mathrm{Cu}, \mathrm{Zn}, \mathrm{Ni}$, Bi e $\mathrm{S}$ refletem a presença de ouro e sulfetos disseminados; de As, Ag, $\mathrm{Bi}$ e $\mathrm{Sb}$ suas concentrações em pirita; e de $\mathrm{Ag}$, Te e Bi suas concentrações em grãos de ouro. As concentrações de $\mathrm{Ba}$ refletem a presença de $\mathrm{BaO}$ em carbonato da alteração hidrotermal, enquanto as de $\mathrm{K}$ decorrem da presença de biotita e sericita como produto da alteração hidrotermal de anfibolito (ocorrência Tapuias) e formação ferrífera bandada (ocorrência Gerseu). As concentrações mais elevadas em W, Mo, Nb e Sr em rochas de alteração hidrotermal da ocorrência Santo Elias resultam, possivelmente, da interação de fluido mineralizador com a rocha granítica hospedeira. Nas ocorrências Gerseu e Tapuias essa interação não ficou evidenciada, possivelmente, pelo fato de que, nelas, o fluido mineralizador percolou, respectivamente, formação ferrífera bandada e anfibolito.

A composição da pirita é, praticamente, a mesma nas três ocorrências, com concentrações mais elevadas de $\mathrm{Zn}$ na ocorrência Gerseu, de Cu nas ocorrências Gerseu e Santo Elias, de Bi na ocorrência Santo Elias e de W nas ocorrências Tapuias e Santo Elias (Tab. 2). Grãos de ouro das três ocorrências apresentam concentrações significativas de $\mathrm{Ag}$, Te e Bi e razão $\mathrm{Au} / \mathrm{Ag}$ com valores comparáveis aos que Cruz (1993) obteve em grãos de ouro da ocorrência Vira-Saia II e do depósito Córrego Paiol (Tab. 3).

\section{ESTUDO DE INCLUSÕES FLUIDAS Ferrari \&} Choudhuri $(2000,2004)$ obtiveram, para temperaturas de homogeneização em inclusões fluidas primárias, secundárias e pseudo-secundárias em quartzo de veios auríferos do depósito Córrego Paiol, valores de 90 a 
Tabela 1 - Concentrações de elementos traço (em ppm), $\mathrm{K}_{2} \mathrm{O}, \mathrm{MgO}$, CaO e S (em \% de peso) em metagranito inalterado (GR) e alterado (GRA) da ocorrência Santo Elias, anfibolito inalterado (ANF) e alterado (ANFA) da ocorrência Tapuias e formação ferrífera bandada inalterada (FF) e alterada (FFA) da ocorrência Gerseu. O valor $<5$ ppm, por exemplo, significa concentração abaixo do limite de detecção do método analítico utilizado.

\begin{tabular}{|c|c|c|c|c|c|c|}
\hline & FF & FFA & GR & GRA & ANF & ANFA \\
\hline $\mathrm{W}$ & 22 & 27 & $<10$ & 13 & 11 & 89 \\
\hline $\mathrm{Y}$ & 5 & 8,35 & 20 & 25 & 20 & 28 \\
\hline $\mathrm{Zn}$ & 20 & 44,58 & 14,5 & 33,24 & 48 & 80 \\
\hline $\mathrm{Zr}$ & 17 & 20 & 12,8 & 12,1 & 57 & 55 \\
\hline $\mathrm{Sr}$ & 8,3 & 17,33 & 246 & 168 & 42 & 64 \\
\hline Mo & 3 & 12 & 7 & 17 & 5 & 8 \\
\hline $\mathrm{Nb}$ & 1 & 3,75 & 2 & 2,5 & 1 & 3 \\
\hline $\mathrm{Ni}$ & 39 & 70 & 18 & 28 & 230 & 410 \\
\hline $\mathrm{Cr}$ & 12 & 5 & 16 & 5 & 80 & 15 \\
\hline $\mathrm{Pb}$ & 3 & 6 & 3 & 15 & $<2$ & $<2$ \\
\hline $\mathrm{Sb}$ & $<5$ & 8 & $<10$ & $<10$ & $<5$ & $<5$ \\
\hline $\mathrm{Sc}$ & $<0,5$ & 7 & 0,80 & 3,16 & 3,1 & 17,3 \\
\hline $\mathrm{Au}$ & 0,014 & 2,73 & 0,016 & 0,13 & 0,1 & 4,16 \\
\hline $\mathrm{Ag}$ & 0,4 & 0,70 & 0,2 & 0,42 & 0,3 & 0,6 \\
\hline As & 11 & 95 & 3 & 14 & $<3$ & 23 \\
\hline $\mathrm{Ba}$ & 16 & 215 & 948 & 2550 & 62 & 100 \\
\hline $\mathrm{Bi}$ & $<5$ & 17 & $<0,5$ & $<0,5$ & $<5$ & $<5$ \\
\hline $\mathrm{Cu}$ & 116 & 563 & 15 & 25 & 40 & 900 \\
\hline $\mathrm{La}$ & 4,29 & 11,8 & 30,56 & 27,50 & & \\
\hline $\mathrm{MgO}$ & 0,28 & 0,83 & 1,52 & 0,98 & 5,02 & 1,85 \\
\hline $\mathrm{CaO}$ & 0,22 & 0,67 & 2,33 & 2,18 & 10,0 & 6,09 \\
\hline $\mathrm{K}_{2} \mathrm{O}$ & 0,23 & 0,38 & 2,50 & 0,23 & 0,25 & 0,69 \\
\hline$S$ & 0,03 & 0,24 & 0,01 & 0,03 & 0,07 & 0,33 \\
\hline
\end{tabular}

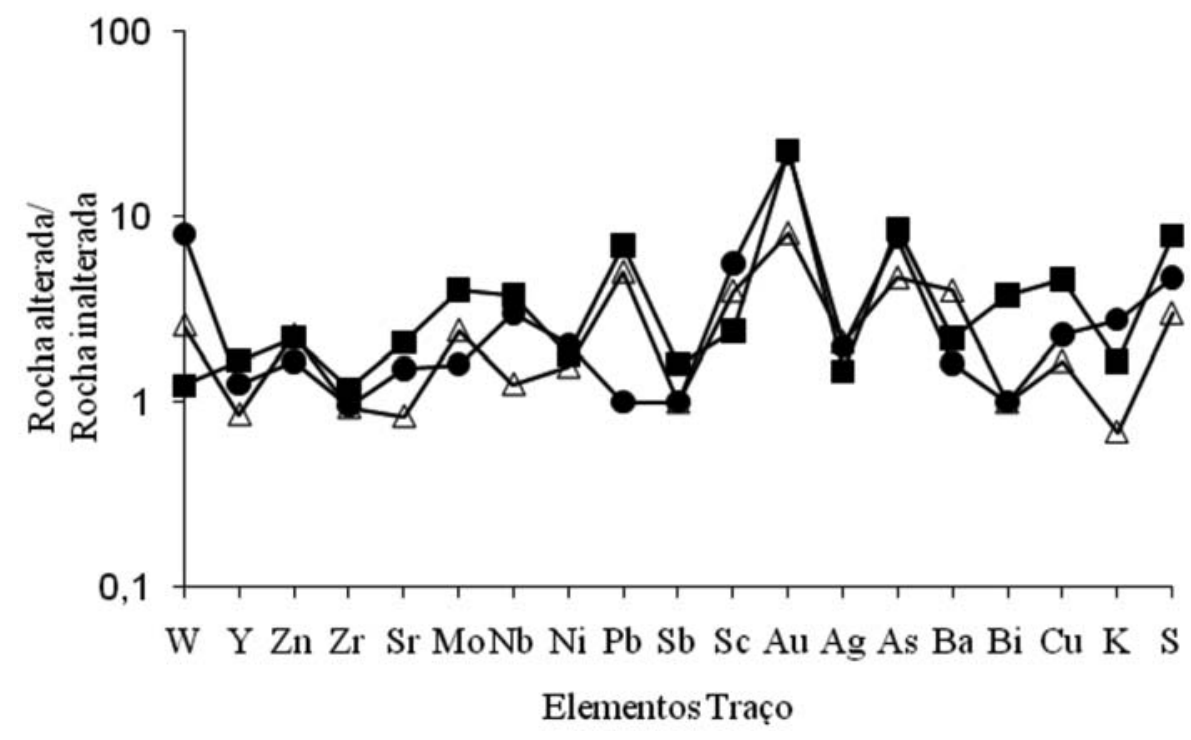

Figura 2 - Padrões de distribuição de elementos traço, potássio e enxofre das zonas de alteração hidrotermal normalizados aos respectivos protolitos. $\Delta$ metagranito, • anfibolito, - formação ferrifera bandada. 
Geologia e ocorrências de ouro do Terreno Granito-Greenstone do Tocantins, TO: sintese do conhecimento e parâmetros para exploração mineral

Tabela 2 - Resultados de análises químicas por microssonda eletrônica em grãos de pirita dos garimpos Gerseu (GE), Tapuias (TA) e Santo Elias (SE). Valores expressos em \% de peso.

\begin{tabular}{ccccccccccc}
\hline & GE-10 & GE-9 & GE-11 & GE-12 & TA-13 & TA-14 & ELI-6 & ELI-7 & ELI-8 \\
\hline $\mathrm{S}$ & 53,92 & 53,12 & 52,56 & 53,13 & 54,17 & 53,90 & 53,88 & 53,30 & 53,84 \\
\hline $\mathrm{Fe}$ & 46,58 & 46,34 & 46,14 & 46,32 & 46,08 & 46,75 & 46,59 & 46,14 & 46,70 \\
\hline $\mathrm{Cu}$ & 0,02 & 0,01 & 0,01 & 0,00 & 0,00 & 0,00 & 0,02 & 0,01 & 0,05 \\
\hline $\mathrm{Zn}$ & 0,00 & 0,02 & 0,04 & 0,04 & 0,00 & 0,00 & 0,00 & 0,00 & 0,00 \\
\hline $\mathrm{Pb}$ & 0,00 & 0,00 & 0,00 & 0,00 & 0,00 & 0,00 & 0,00 & 0,00 & 0,00 \\
\hline $\mathrm{Sb}$ & 0,00 & 0,00 & 0,00 & 0,00 & 0,00 & 0,00 & 0,01 & 0,00 & 0,00 \\
\hline $\mathrm{Bi}$ & 0,00 & 0,00 & 0,00 & 0,00 & 0,00 & 0,00 & 0,05 & 0,02 & 0,00 \\
\hline $\mathrm{Ni}$ & 0,05 & 0,02 & 0,02 & 0,00 & 0,10 & 0,01 & 0,05 & 0,00 & 0,03 \\
\hline $\mathrm{As}$ & 0,18 & 0,12 & 0,38 & 0,42 & 0,21 & 0,13 & 0,17 & 0,13 & 0,23 \\
\hline $\mathrm{Cd}$ & 0,00 & 0.00 & 0,01 & 0,00 & 0,00 & 0,00 & 0,00 & 0,00 & 0,02 \\
\hline $\mathrm{Co}$ & 0,00 & 0,04 & 0,00 & 0,00 & 0,01 & 0,00 & 0,04 & 0,00 & 0,00 \\
\hline $\mathrm{Ag}$ & 0,00 & 0,03 & 0,00 & 0,04 & 0,07 & 0,00 & 0,10 & 0,00 & 0,03 \\
\hline $\mathrm{W}$ & 0,00 & 0,01 & 0,00 & 0,02 & 0,11 & 0,00 & 0,06 & 0,00 & 0,00 \\
\hline $\mathrm{Sn}$ & 0,01 & 0,00 & 0,02 & 0,03 & 0,03 & 0,01 & 0,00 & 0,04 & 0,00 \\
\hline $\mathrm{Total}$ & 100,76 & 99,71 & 99,18 & 100,00 & 100,73 & 100,80 & 100,97 & 99,64 & 100,90 \\
\hline & & & & & & &
\end{tabular}

Tabela 3 - Resultados de análises químicas por microssonda eletrônica em grãos de ouro dos garimpos Gerseu (GE), Tapuias (TA) e Santo Elias (SE). Valores expressos em \% de peso.

\begin{tabular}{ccccccccccc}
\hline & GE-2 & GE-3 & GE-5 & GE-6 & ELI-1 & ELI-5 & ELI-9 & TA-4 & TA-5 \\
\hline $\mathrm{Au}$ & 95,13 & 95,04 & 95,13 & 94,98 & 81,67 & 81,11 & 82,05 & 91,79 & 91,88 \\
\hline $\mathrm{Cu}$ & 0,05 & 0,05 & 0,04 & 0,02 & 0,01 & 0,05 & 0,01 & 0,10 & 0,03 \\
\hline $\mathrm{Fe}$ & 0,02 & 0,53 & 0,05 & 0,01 & 0,00 & 0,00 & 0,00 & 0,10 & 0,58 \\
\hline $\mathrm{Ag}$ & 5,45 & 5,22 & 5,57 & 5,66 & 18,54 & 18,76 & 18,77 & 6,91 & 6,88 \\
\hline $\mathrm{Pd}$ & 0,00 & 0,00 & 0,00 & 0,00 & 0,00 & 0,00 & 0,00 & 0,00 & 0,00 \\
\hline $\mathrm{Te}$ & 0,02 & 0,00 & 0,04 & 0,02 & 0,00 & 0,01 & 0,04 & 0,20 & 0,00 \\
\hline $\mathrm{Bi}$ & 0,27 & 0,08 & 0,15 & 0,15 & 0,37 & 0,10 & 0,08 & 0,00 & 0,05 \\
\hline $\mathrm{Total}$ & 100,94 & 100,98 & 100,98 & 100,84 & 100,59 & 100,03 & 100,95 & 99,10 & 99,42 \\
\hline $\mathrm{Au} / \mathrm{Ag}$ & 17,45 & 18,21 & 17,08 & 16,78 & 4,40 & 4,32 & 4,37 & 13,28 & 13,35 \\
\hline
\end{tabular}

$320^{\circ} \mathrm{C}$ para inclusões fluidas tipo I, bifásicas com líquido aquoso predominante e salinidade mais baixa $(15 \%$ $\mathrm{NaCl}$ eq.), pertencentes ao sistema $\mathrm{H}_{2} \mathrm{O}-\mathrm{MgO}-\mathrm{NaCl}$; de 210 a $410^{\circ} \mathrm{C}$ para inclusões fluidas do tipo II, trifásicas com salinidade mais elevada ( $35 \%$ de $\mathrm{NaCl}$ eq.) e pertencentes ao sistema $\mathrm{H}_{2} \mathrm{O}-\mathrm{CaCl}_{2}-\mathrm{NaCl}$; e tipo III, secundárias e monofásicas (líquido aquoso). Segundo aqueles autores, os dados obtidos indicam processo de ebulição e composição aquossalina para os fluidos hidrotermais, responsáveis pelo retrometamorfismo das rochas do TGGT para a fácies xisto verde em zonas de cisalhamento do evento $\mathrm{D}_{2}$ e, ao final deste, pelo processo hidrotermal que originou o depósito.
Os dados apresentados neste trabalho foram obtidos em quartzo de veios auríferos das ocorrências Santo Elias, Tapuias e Gerseu. Os dados de microtermometria foram obtidos no Instituto de Geociências da Universidade de Brasília, utilizando-se platina Linkam THMSG 600/TMS 93, com sistema de resfriamento LNP 2. A calibração do equipamento foi realizada utilizando-se inclusões fluidas de padrões sintéticos FLUID INC. A reprodutibilidade dos dados foi de $0,2^{\circ} \mathrm{C}$ entre $-60^{\circ}$ e $30^{\circ} \mathrm{C}$ e de $2^{\circ} \mathrm{C}$ para temperaturas acima deste valor.

Pretende-se que tais dados, embora preliminares, possam motivar novos estudos em inclusões fluidas que 
possibilitem aprimorar o entendimento sobre a mineralização de ouro no TGGT.

Tipos de inclusões fluidas Os estudos petrográfico e microtermométrico possibilitaram distinguir diferentes populações de inclusões fluidas, que se agrupam, genericamente, nos seguintes tipos: aquocarbônicas bifásicas e trifásicas com características petrográficas de inclusões primárias (tipo 1); raras inclusões monofásicas e bifásicas carbônicas (Tipo 1b); aquosas (Tipo 2) com características petrográficas de inclusões primárias (tipo 2a) e de inclusões secundárias (Tipo 2b) (Tab. 4).

OCORRENCIA SANTO ELIAS (biotita granito) Nesta ocorrência foram identificados os seguintes tipos de inclusões fluidas:

Tipo 1 - inclusões fluidas aquocarbônicas bifásicas $\left(\mathrm{L}_{\mathrm{H} 2 \mathrm{O}}+\mathrm{L}_{\mathrm{CO} 2}\right)$ e trifásicas $\left(\mathrm{L}_{\mathrm{H} 2 \mathrm{O}}+\mathrm{L}_{\mathrm{CO} 2}+\mathrm{V}_{\mathrm{CO} 2}\right)$ (Fig. 3a), com dimensões entre 5 e $15 \mu \mathrm{m}$ e volume da fase gás/volume total $(\mathrm{Vg})$ variando de 10 a $30 \%$, intragranulares e isoladas nos grãos de quartzo, o que possibilitou interpretá-las como primárias. A fase carbônica apresentou $\mathrm{Tf}_{\mathrm{CO} 2}$ entre $-57,6^{\circ} \mathrm{C}$ e $-56,6^{\circ} \mathrm{C}$, com moda próxima de $-56,6^{\circ} \mathrm{C}$ (Fig. 4a). A temperatura de fusão do clatrato varia de $-13,1$ a $6^{\circ} \mathrm{C}$, com predomínio de valores positivos (Fig. 4b), enquanto a temperatura do ponto eutético (Te) da fase aquosa situa-se entre $-52^{\circ} \mathrm{C}$ e $-40^{\circ} \mathrm{C}$ ). A homogeneização da fase carbônica ocorre no estado líquido, entre $-1^{\circ} \mathrm{C}$ e $30^{\circ} \mathrm{C}$, predominantemente entre $20^{\circ} \mathrm{C}$ e $30^{\circ} \mathrm{C}$ (Fig. 4c). A homogeneização total ocorre para o líquido aquoso entre $232^{\circ} \mathrm{C}$ e $356^{\circ} \mathrm{C}$, com moda entre $280^{\circ} \mathrm{C}$ e $300^{\circ} \mathrm{C}$ (Fig. 4d). Os valores de temperatura de eutético da fase aquosa e os dados de fusão da fase carbônica permitem modelar o sistema como $\mathrm{H}_{2} \mathrm{O}-\mathrm{CO}_{2}-\mathrm{NaCl}-\mathrm{CaCl}_{2}$ (Oakes et al. 1990). A existência de valores de $\mathrm{Tf}_{\mathrm{CO} 2}$ menores que $-56,6^{\circ} \mathrm{C}$ indica possível presença de $\mathrm{CH}_{4}$ ou $\mathrm{N}_{2}$ na fase carbônica, cuja confirmação depende de análises por espectroscopia Raman. A salinidade, calculada com base na temperatura de fusão do clatrato (Diamond 1992), situa-se entre $7 \%$ e $26 \%$ em peso de $\mathrm{NaCl}$ eq., com concentração de valores de 10 a $13 \%$ em peso de $\mathrm{NaCl}$ eq. A densidade da fase carbônica varia, predominantemente, entre $0,60 \mathrm{~g} / \mathrm{cm}^{3}$ e $0,76 \mathrm{~g} / \mathrm{cm}^{3}$, utilizando a fórmula de Brown \& Lamb (1986).

Tipo 2a - inclusões fluidas aquosas bifásicas, irregulares, raras, com características petrográficas de inclusões primárias, frequentemente estranguladas, e com dimensões que variam de 4 a $12 \mu \mathrm{m}$. A Te situa-se entre $-47^{\circ} \mathrm{C}$ e $-40^{\circ} \mathrm{C}$ (Tab.4, Fig. 4e), a temperatura de fusão

Tabela 4 - Resumo dos dados de inclusões fluidas das ocorrências de ouro estudadas.

\begin{tabular}{|c|c|c|c|}
\hline Tipo de inclusão fluida & Garimpo & $\begin{array}{l}\text { Características } \\
\text { petrográficas }\end{array}$ & $\begin{array}{c}\text { Principais dados } \\
\text { microtermométricos }\end{array}$ \\
\hline $\begin{array}{c}\text { Tipo 1a }\left(\mathrm{L}_{\mathrm{H} 2 \mathrm{O}}+\mathrm{L}_{\mathrm{CO} 2}+\mathrm{V}_{\mathrm{CO} 2}\right) \\
\mathrm{H}_{2} \mathrm{O}-\mathrm{CO}_{2}-\mathrm{NaCl}-\mathrm{CaCl}_{2}\left( \pm \mathrm{CH}_{4}\right)\end{array}$ & Santo Elias & $\begin{array}{l}\text { Arredondadas, irregulares, } \\
\text { primárias. Fase sólida birre- } \\
\text { fringente comum. } \mathrm{Vg}>30 \text {. } \\
5-10 \mu \mathrm{m} \text {. }\end{array}$ & $\begin{array}{c}\mathrm{TfCO}_{2}=-57,6^{\circ} \text { a }-56,6^{\circ} \mathrm{C} \\
\text { Tfclat }=-13,1^{\circ} \text { a } 6,0^{\circ} \mathrm{C} \\
\operatorname{ThCO}_{2}(\mathrm{~L})=-1,4^{\circ} \text { a } 29,6^{\circ} \mathrm{C} \\
\text { Thtot }(\mathrm{L})=232^{\circ} \text { a } 356^{\circ} \mathrm{C}\end{array}$ \\
\hline $\begin{array}{c}\text { Tipo } 1 \mathrm{a}\left(\mathrm{L}_{\mathrm{H} 2 \mathrm{O}}+\mathrm{L}_{\mathrm{CO} 2}+\mathrm{V}_{\mathrm{CO} 2}\right) \\
\mathrm{H}_{2} \mathrm{O}-\mathrm{CO}_{2}-\mathrm{NaCl}-\mathrm{CaCl}_{2}\left( \pm \mathrm{CH}_{4}\right)\end{array}$ & Gerseu/Igrejinha & $\begin{array}{l}\text { Arredondadas, irregulares, } \\
\text { primárias. } \\
5-12 \mu \mathrm{m} .\end{array}$ & $\begin{array}{c}\mathrm{TfCO}_{2}=-56,6^{\circ} \mathrm{C} \\
\text { Tfclat }=7,2^{\circ} \text { a } 7,8^{\circ} \mathrm{C} ; \\
\mathrm{ThCO}_{2}(\mathrm{~L})=19,4^{\circ} \text { a } 30,1^{\circ} \mathrm{C} ; \\
\text { Thtot }(\mathrm{L})=235^{\circ} \text { a } 324^{\circ} \mathrm{C}\end{array}$ \\
\hline $\begin{array}{c}\text { Tipo 2a }\left(\mathrm{L}_{\mathrm{H} 2 \mathrm{O}}+\mathrm{V}_{\mathrm{H} 2 \mathrm{O}}\right) \\
\mathrm{H}_{2} \mathrm{O}-\mathrm{NaCl}-\mathrm{CaCl}_{2}\left( \pm \mathrm{MgCl}_{2} \pm \mathrm{FeCl}_{2}\right)\end{array}$ & Santo Elias & $\begin{array}{c}\text { Irregulares. Estrangulamento } \\
\text { frequente. Primárias. } \\
4-12 \mu \mathrm{m} \text {. }\end{array}$ & $\begin{array}{c}\mathrm{Te}=-47,1 \mathrm{a}-32,2^{\circ} \mathrm{C} \\
\mathrm{Tfg}=-18,8^{\circ} \text { a }-4,5^{\circ} \mathrm{C} \\
\text { Thtot }(\mathrm{L})=223^{\circ} \text { a } 338^{\circ} \mathrm{C}\end{array}$ \\
\hline $\begin{array}{c}\text { Tipo 2a }\left(\mathrm{L}_{\mathrm{H} 2 \mathrm{O}}+\mathrm{V}_{\mathrm{H} 2 \mathrm{O}}\right) \\
\mathrm{H}_{2} \mathrm{O}-\mathrm{NaCl}-\mathrm{CaCl}_{2}\left( \pm \mathrm{MgCl}_{2} \pm \mathrm{FeCl}_{2}\right)\end{array}$ & Tapuias & $\begin{array}{l}\text { Arredondadas, primárias. } \\
\qquad 5-8 \mu \mathrm{m} .\end{array}$ & $\begin{array}{c}\mathrm{Te}=-45,7^{\circ} \text { a }-26,5^{\circ} \mathrm{C} \\
\mathrm{Tfg}=-1,8^{\circ} \text { a }-0,5^{\circ} \mathrm{C} \\
\text { Thtot }(\mathrm{L})=308^{\circ} \text { a } 346^{\circ} \mathrm{C}\end{array}$ \\
\hline $\begin{array}{c}\text { Tipo } 2\left(\mathrm{~L}_{\mathrm{H} 2 \mathrm{O}}+\mathrm{V}_{\mathrm{H} 2 \mathrm{O}}\right) \\
\mathrm{H}_{2} \mathrm{O}-\mathrm{NaCl}-\mathrm{CaCl}_{2}\left( \pm \mathrm{MgCl}_{2} \pm \mathrm{FeCl}_{2}\right)\end{array}$ & Gerseu/Igrejinha & $\begin{array}{l}\text { Irregulares, difícil distinção } \\
\text { entre secundária e primária. } \\
\text { 4-15 } \mu \mathrm{m} \text {. }\end{array}$ & $\begin{array}{c}\mathrm{Te}=-53^{\circ} \text { a }-20,2^{\circ} \mathrm{C} \\
\mathrm{Tfhidr} \approx-22,0^{\circ} \mathrm{C} \\
\mathrm{Tfg}=-12,3^{\circ} \mathrm{a}-0,1^{\circ} \mathrm{C} \\
\text { Thtot }(\mathrm{L})=120^{\circ} \text { a } 315^{\circ} \mathrm{C}\end{array}$ \\
\hline $\begin{array}{c}\text { Tipo } 2 \mathrm{~b}\left(\mathrm{~L}_{\mathrm{H} 2 \mathrm{O}}+\mathrm{V}_{\mathrm{H} 2 \mathrm{O}}\right) \\
\mathrm{H}_{2} \mathrm{O}-\mathrm{NaCl}-\mathrm{CaCl}_{2}\left( \pm \mathrm{MgCl}_{2} \pm \mathrm{FeCl}_{2}\right)\end{array}$ & Santo Elias & $\begin{array}{l}\text { Irregulares, arredondadas, } \\
\text { secundárias. } \\
4-9 \mu \mathrm{m} .\end{array}$ & $\begin{array}{c}\mathrm{Te}=-53,7 \text { a }-20,8^{\circ} \mathrm{C} \\
\text { Tfhidr }=-34,1^{\circ} \text { a }-20,8^{\circ} \mathrm{C} \\
\text { Tfg }=-17,7^{\circ} \text { a }-1,9^{\circ} \mathrm{C} \\
\text { Thtot }(\mathrm{L})=123^{\circ} \text { a } 215^{\circ} \mathrm{C}\end{array}$ \\
\hline $\begin{array}{l}\text { Tipo } 2 \mathrm{~b}\left(\mathrm{~L}_{\mathrm{H} 2 \mathrm{O}}+\mathrm{V}_{\mathrm{H} 2 \mathrm{O}}\right) \\
\mathrm{H}_{2} \mathrm{O}-\mathrm{NaCl}-\mathrm{CaCl}_{2}\end{array}$ & Tapuias & $\begin{array}{l}\text { Irregulares, secundárias. } \\
\qquad 7-15 \mu \mathrm{m} .\end{array}$ & $\begin{array}{c}\mathrm{Te}=-47,3^{\circ} \text { a }-42,6^{\circ} \mathrm{C} \\
\mathrm{Tfg}=-15,6^{\circ} \text { a }-12,3^{\circ} \mathrm{C} \\
\text { Thtot }(\mathrm{L})=127^{\circ} \text { a } 181^{\circ} \mathrm{C}\end{array}$ \\
\hline
\end{tabular}


do gelo $\left(\mathrm{Tf}_{\mathrm{g}}\right.$ ) varia de $-18,8 \mathrm{a}-4,5^{\circ} \mathrm{C}$ (Tab. 4, Fig. 4f) e a $\mathrm{Th}$, entre $223^{\circ} \mathrm{C}$ e $338^{\circ} \mathrm{C}$, com moda entre $260^{\circ} \mathrm{C}$ e $300^{\circ} \mathrm{C}$ (Fig. 4g). As temperaturas de primeira fusão (Te) predominantemente abaixo de $-40^{\circ} \mathrm{C}$ permitem utilizar o sistema $\mathrm{H}_{2} \mathrm{O}-\mathrm{NaCl}-\mathrm{CaCl}_{2}$ como modelo para este tipo de inclusão fluida da ocorrência Santo Elias. Entretanto, a obtenção de alguns dados de Te de até $-32^{\circ} \mathrm{C}$ pode sugerir a presença de outros cátions divalentes no sistema, como $\mathrm{Mg}^{2+} \mathrm{e} \mathrm{Fe}^{2+}$ (Davis et al. 1990, Oakes et al. 1990, Goldstein \& Reynolds, 1994). A salinidade situa-se entre $10 \%$ e $22 \%$ em peso de $\mathrm{NaCl}$ eq. (Fig. 4 h), estimativa obtida com base na temperatura de fusão do gelo (Bodnar 1993). A densidade, calculada segundo Zhang \& Frantz (1987), varia de 0,85 a $0,98 \mathrm{~g} / \mathrm{cm}^{3}$.

Tipo $2 b$ - inclusões fluidas aquosas bifásicas, com dimensões de 4 a $9 \mu \mathrm{m}$, com $\mathrm{Vg}<10 \%$, predominantes, alinhadas ao longo de trilhas intergranulares, interpretadas como secundárias (Fig. 3b). A primeira fusão (Te) ocorre entre $-52^{\circ} \mathrm{C}$ e $-20,8^{\circ} \mathrm{C}$. A fusão da hidrohalita, quando observada, ocorre de -34 a $-27^{\circ} \mathrm{C}$. A temperatura de fusão do gelo varia de -18 a $-1,9^{\circ} \mathrm{C}$ com moda de $-10 \mathrm{a}-6^{\circ} \mathrm{C}$ (Fig. 4f). A $\mathrm{Th}_{t}$ situa-se entre $123^{\circ} \mathrm{C}$ e $215^{\circ} \mathrm{C}$, com moda entre $180^{\circ} \mathrm{C}$ e $215^{\circ} \mathrm{C}$ (Fig. $4 \mathrm{~g}$ ). O sistema foi modelado como $\mathrm{H}_{2} \mathrm{O}-\mathrm{NaCl}-\mathrm{CaCl}_{2}\left( \pm \mathrm{MgCl}_{2} \pm \mathrm{FeCl}_{2}\right)$, com base nas temperaturas de fusão do eutético (Davis et al. 1990; Oakes et al. 1990; Goldstein \& Reynolds 1994) e na geologia da área. A salinidade total, estimada segundo Bodnar (1993), varia de 3,5 a 21\% em peso de $\mathrm{NaCl}$ eq., com concentração de valores entre $9 \%$ e $14 \%$ em peso de $\mathrm{NaCl}$ eq. (Fig. 4h). A temperatura de fusão de hidrohalita permitiu obter valores de 0,25 a 0,55 para a razão $\mathrm{NaCl} /\left(\mathrm{NaCl}+\mathrm{CaCl}_{2}\right)$ das inclusões $\mathrm{H}_{2} \mathrm{O}-\mathrm{NaCl}-\mathrm{CaCl}_{2}$, com base em Oakes et al. (1990). A densidade, calculada segundo Zhang \& Frantz (1987), varia de 0,98 a $1,0 \mathrm{~g} / \mathrm{cm}^{3}$.

OCORRENCIA TAPUIAS (anfibolito) Nesta ocorrência, as inclusões fluidas nas amostras estudadas são raras e compreendem duas populações, denominadas tipos $2 \mathrm{a}$ e $2 \mathrm{~b}$ para fins de comparação com as demais ocorrências estudadas (Tab. 4).

Tipo 2a - inclusões fluidas aquosas bifásicas, com $\mathrm{Vg}$ de, predominantemente, 10 a $20 \%$, menores que $8 \mu \mathrm{m}$, arredondadas, caracterizadas por encontrarem-se isoladas no interior de partes não recristalizadas do quartzo, o que permitiu interpretá-las como primárias (Fig. 3c). A temperatura do eutético varia de -47 a $-26,5^{\circ} \mathrm{C}$, com concentração de valores entre $-27^{\circ} \mathrm{C}$ e $-26,5^{\circ} \mathrm{C}$ (Fig. $4 \mathrm{e}$ ). A Tf varia de $-1,8$ a $-0,5^{\circ} \mathrm{C}$ (Fig. 4f, Tab. 4). A $\mathrm{Th}_{\mathrm{t} 1}$ ocorre entre $300^{\circ} \mathrm{C}$ e $350^{\circ} \mathrm{C}$, para o líquido (Tab. 4, Fig. 4g). As temperaturas de primeira fusão (Te) são coerentes com o sistema $\mathrm{H}_{2} \mathrm{O}-\mathrm{NaCl}$ $\mathrm{CaCl}_{2}\left( \pm \mathrm{MgCl}_{2} \pm \mathrm{FeCl}_{2}\right)$ para modelar o fluido (Shepherd et al. 1985; Davis et al. 1990; Goldstein \& Reynolds
1994). Os valores de Te entre $-27^{\circ} \mathrm{C}$ e $-26,5^{\circ} \mathrm{C}$ (Fig.4e) podem estar relacionados à presença de cátions divalentes $\left(\mathrm{Fe}^{2+} \mathrm{e} / \mathrm{ou} \mathrm{Mg}^{2+}\right)$ no sistema, mas também representar eutético metaestável do sistema $\mathrm{H}_{2} \mathrm{O}-\mathrm{NaCl}$ (Crawford 1981; Shepherd et al. 1985; Davis et al. 1990). A salinidade situa-se entre $1 \%$ e $3 \%$ em peso de $\mathrm{NaCl}$ eq. (Fig. 4h), calculada com base na temperatura de fusão do gelo (Bodnar 1993). A densidade, calculada segundo Zhang \& Frantz (1987), varia de 0,64 a $0,74 \mathrm{~g} / \mathrm{cm}^{3}$.

Tipo $2 \mathbf{b}$ - inclusões fluidas aquosas bifásicas, com Vg, predominantemente, em torno de $10 \%$, formas irregulares, estranguladas, interpretadas como secundárias por se distribuírem ao longo de fraturas que ultrapassam grãos individuais de quartzo (Fig. 3d). A temperatura do eutético situa-se entre $-48^{\circ} \mathrm{C}$ e $-43^{\circ} \mathrm{C}$ (Fig. 4e), enquanto a fusão do gelo ocorre entre $-15,6^{\circ} \mathrm{C}$ e $-12,3^{\circ} \mathrm{C}$ (Fig. 4f, Tab. 4). A homogeneização total ocorre para o líquido, de 130 a $181^{\circ} \mathrm{C}$ (Fig. $4 \mathrm{~g}$ ). Os dados de Te (Fig. 4e) permitem modelar o fluido pelo sistema $\mathrm{H}_{2} \mathrm{O}-\mathrm{NaCl}-\mathrm{CaCl}_{2}$ (Davis et al. 1990; Oakes et al. 1990; Goldstein \& Reynolds 1994). A salinidade, estimada com base na temperatura de fusão do gelo (Bodnar 1993), situa-se entre $16 \%$ e $19 \%$ em peso de $\mathrm{NaCl}$ eq. (Fig. 4h). A densidade, calculada de acordo com Zhang \& Frantz (1987), varia de 1,01 a 1,06 g/ $\mathrm{cm}^{3}$.

OCORRENNCIA GERSEU (formação ferrífera bandada) Nesta ocorrência, foram identificadas as populações de inclusões fluidas classificadas como tipos 1 e 2 .

Tipos 1a e 1b - inclusões fluidas carbônicas $\left(\mathrm{CO}_{2}\right)$ bifásicas e monofásicas, escuras, raras (Fig. 3e, Tipo 1b), e aquo-carbônicas bifásicas e trifásicas, escuras, (Fig. 3f, Tipo 1a), de 5 a $12 \mu \mathrm{m}$, com Vg variando de 20 a $40 \%$ e $\mathrm{Tf}_{\mathrm{CO} 2}$ em torno de $-56,6^{\circ} \mathrm{C}$ (Fig. 4a). Não foi possível observar a Te da fase aquosa das inclusões fluidas do tipo 1a. A $\mathrm{Tf}_{\text {clat }}$ das inclusões do tipo 1a ocorre entre $7,2^{\circ} \mathrm{C}$ e $7,8^{\circ} \mathrm{C}$ (Fig. 4b), a $\mathrm{Th}_{\mathrm{CO} 2}$ das inclusões dos tipos $1 \mathrm{a}$ e $1 \mathrm{~b}$ ocorre entre $19^{\circ} \mathrm{C}$ e $30,1^{\circ} \mathrm{C}$, para o estado líquido (Fig. 4c) e a $\mathrm{Th}_{\text {total }}$ das inclusões aquo-carbônicas (tipo 1a) situa-se entre $235^{\circ} \mathrm{C}$ e $324^{\circ} \mathrm{C}$, com moda entre $280^{\circ} \mathrm{C}$ e $300^{\circ} \mathrm{C}$ (Fig. 4d). As inclusões fluidas dos tipos $1 \mathrm{~b}$ e 1a foram modeladas, respectivamente, pelos sistemas $\mathrm{CO}_{2} \mathrm{e}$ $\mathrm{H}_{2} \mathrm{O}-\mathrm{CO}_{2}-\mathrm{NaCl}$ (Shepherd et al. 1985). A salinidade das inclusões do tipo 1a, estimada com base na $\mathrm{Tf}_{\text {clat }}$, varia de 4 a $6 \%$ em peso de $\mathrm{NaCl}$ eq. (Fig. 4h). A densidade da fase carbônica varia de 0,71 a $0,77 \mathrm{~g} / \mathrm{cm}^{3}$, de acordo com Brown \& Lamb (1986).

Tipo 2 - inclusões fluidas aquosas, bifásicas, com dimensões de 4 a $15 \mu \mathrm{m}$, formas irregulares e Vg de 5 a $20 \%$. A distinção petrográfica entre inclusões fluidas primárias e secundárias é bastante difícil, tendo em vista o aspecto turvo do quartzo e a existência de muitas trilhas de inclusões fluidas de diferentes direções, dificultando a observação de inclusões intragranulares 

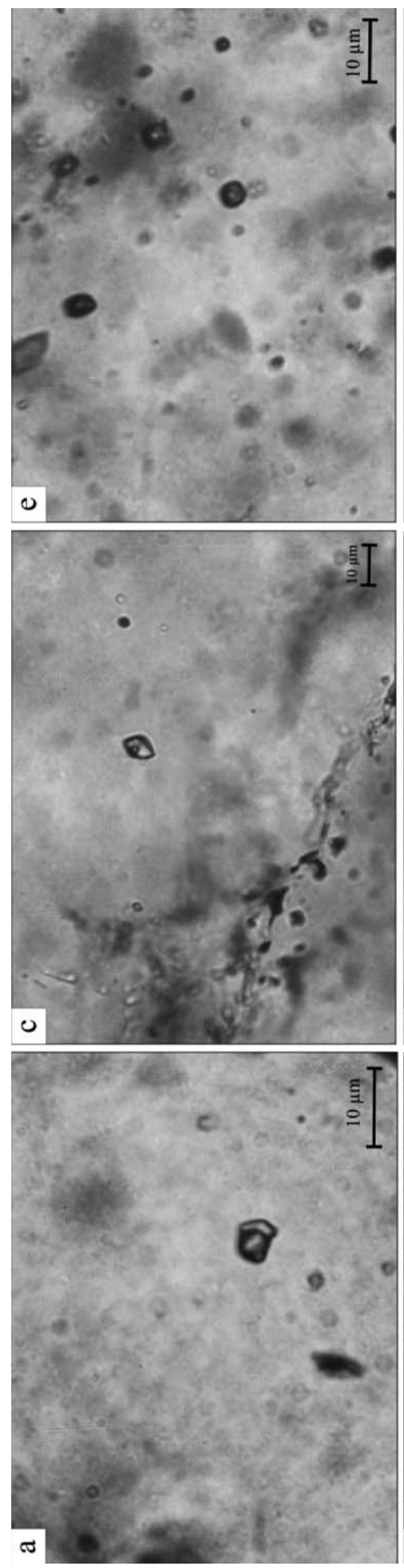
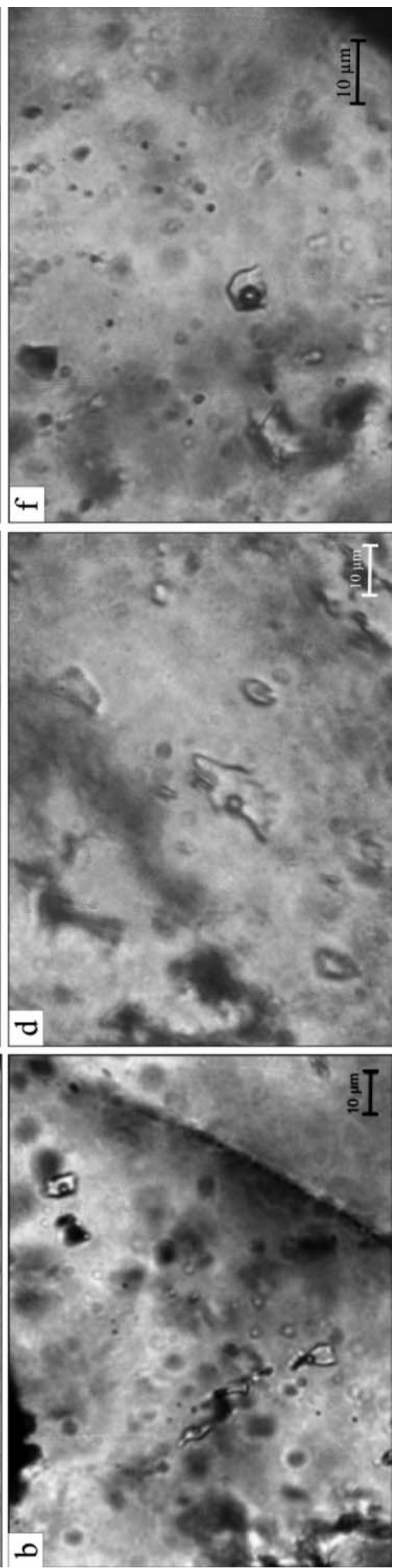

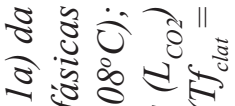
잉

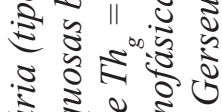
\& 80 व

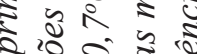

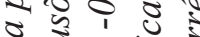

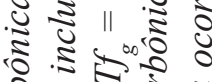

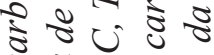

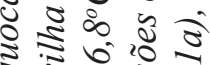

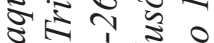
\& $211 \stackrel{5}{5}$ 的告告 ₹. ह हิ के 0 . 胥 5

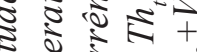
के 008 ข $\therefore \approx$ : 8 i

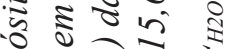
क्ष व क्ष ₹

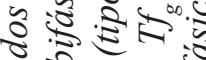

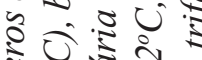
के छै त 莎 - 1111 ๑ ฐ

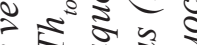
$\therefore 0$ \% ० 0.0 . 党 के +3.5 2. 11000 ₹ 218 सह 52 य 2 8 อ $\frac{2}{2}$ i

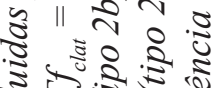
s. पे पे है

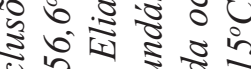
ใน $\approx \| \lesssim \approx$ \& हु

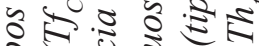
उ प 50 . है

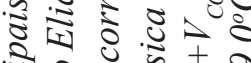
: 080

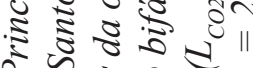

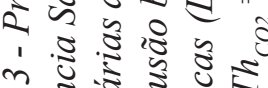

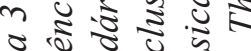

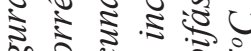

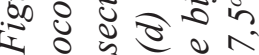



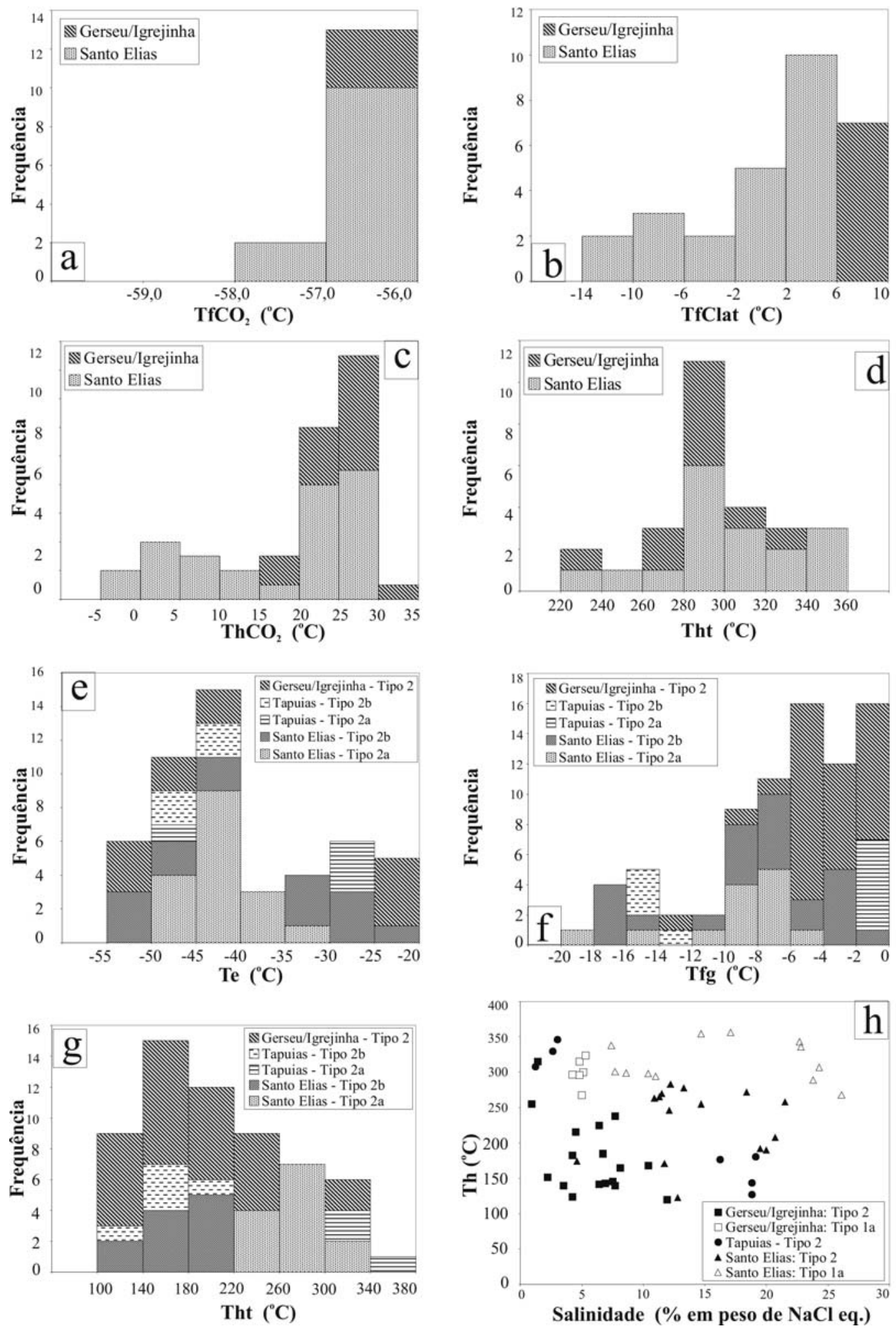

Figura 4 - Histogramas de frequência de inclusões fluidas aquocarbônicas dos depósitos Santo Elias, Tapuias e Gerseu/Igrejinha. (a) temperatura de fusão de $\mathrm{CO}_{2}$ de inclusões fluidas aquocarbônicas e carbônicas (Tipos la e 1b); (b) temperatura de fusão do clatrato de inclusões fluidas do Tipo la; (c) temperatura de homogeneização de $\mathrm{CO}_{2}$ de inclusões fluidas aquocarbônicas e carbônicas (Tipos 1a e 1b); (d) temperatura de homogeneização total de inclusões fuidas aquocarbônicas (Tipo la); (e) temperatura do ponto eutético de inclusões fluidas bifásicas aquosas (Tipo 2); (f) temperatura de fusão do gelo de inclusões fluidas do Tipo 2; (g) temperatura de homogeneização total de inclusões fluidas do Tipo 2; (h) diagrama binário de salinidade x temperatura de homogeneização total para as inclusões dos Tipos 1 e 2. 
isoladas. A temperatura do ponto eutético varia de -53 a $-20,2^{\circ} \mathrm{C}$, com moda entre -53 e $-45^{\circ} \mathrm{C}$ (Tab. 4, Fig. $4 \mathrm{e})$. A fusão da hidrohalita ocorre de -22 a $-20^{\circ} \mathrm{C}$, enquanto a fusão do gelo ocorre entre $-12,3^{\circ}$ e $-0,1^{\circ} \mathrm{C}$, com moda de -6 a $-0,5^{\circ} \mathrm{C}$ (Fig. 4f). A $\mathrm{Th}_{\text {total }}$ está entre $120^{\circ} \mathrm{C}$ e $315^{\circ} \mathrm{C}$, com predomínio de valores entre $120^{\circ} \mathrm{C}$ e $200^{\circ} \mathrm{C}$ (Fig. $4 \mathrm{~g}$ ). O fluido foi modelado pelo sistema $\mathrm{H}_{2} \mathrm{O}-\mathrm{NaCl}-\mathrm{CaCl}_{2}$, com base nas temperaturas de fusão do eutético, podendo conter $\mathrm{MgCl}_{2}$ e $\mathrm{FeCl}_{2}$ (Davis et al. 1990, Oakes et al. 1990, Goldstein \& Reynolds 1994). A salinidade total, estimada segundo Bodnar (1993), varia de 0,9 a $16,2 \%$ em peso de $\mathrm{NaCl}$ eq., com concentração de valores entre $5 \%$ e $8 \%$ em peso de $\mathrm{NaCl}$ eq. (Fig. 4h). A temperatura de fusão de hidrohalita indica valores de, aproximadamente, 0,9 para a razão $\mathrm{NaCl} /\left(\mathrm{NaCl}+\mathrm{CaCl}_{2}\right)$ para o sistema $\mathrm{H}_{2} \mathrm{O}-\mathrm{NaCl}-\mathrm{CaCl}_{2}$, com base em Oakes et al. (1990). A densidade, calculada segundo Zhang \& Frantz (1987), varia de 0,88 a $0,95 \mathrm{~g} / \mathrm{cm}^{3}$.

Interpretação dos dados de inclusões fluidas As inclusões fluidas dos tipos 1 e 2 coexistem nos mesmos cristais de quartzo, indicando que os fluidos aquocarbônicos e aquosos primários podem ter sido contemporâneos. Não foi possível estimar temperatura e pressão de aprisionamento por meio do cruzamento de isócoras dos diferentes sistemas, tendo em vista não haver evidências claras de que os fluidos sejam cogenéticos, principalmente devido à existência de fluidos tardios que se sobrepuseram aos fluidos primários.

As inclusões fluidas interpretadas como primárias possuem densidades inferiores às secundárias e, dentre as primárias, os fluidos aquocarbônicos têm densidades mais baixas. Os fluidos de temperatura mínima de aprisionamento e salinidade mais elevadas são os fluidos primários aquocarbônicos da ocorrência Santo Elias, em biotita granito. As inclusões fluidas aquosas primárias da ocorrência Santo Elias apresentam temperatura de homogeneização total entre $250^{\circ} \mathrm{C}$ e $300^{\circ} \mathrm{C}$ e salinidade variável, o que pode ser devido à mistura de fluidos magmático e metamórfico, decorrente dos diferentes processos geológicos que ocorreram na região. Ambos fluidos contêm $\mathrm{CaCl}_{2}$ na sua composição química, além de provavelmente $\mathrm{Mg}$ e Fe, o que é compatível com a composição dos veios e o tipo de alteração hidrotermal interpretada como estando em equilíbrio com a mineralização em Santo Elias, descrita no presente trabalho. Na ocorrência Tapuias, as inclusões fluidas aquosas primárias revelam elevada temperatura de homogeneização total e baixa salinidade. $\mathrm{O}$ fluido mostra composição complexa, $\mathrm{H}_{2} \mathrm{O}-\mathrm{NaCl}-\mathrm{CaCl}_{2}\left( \pm \mathrm{MgCl}_{2} \pm \mathrm{FeCl}_{2}\right)$, porém, coerente com fluido mineralizador metamórfico em que houve importante contribuição da rocha básica hospedeira na sua geração. Na ocorrência Gerseu, os fluidos considerados primários apresentam elevada temperatura de homogeneização total e baixa salinidade, características coerentes com fluido metamórfico. A predominância de inclusões fluidas secundárias de elevada densidade e variadas salinidade e temperatura de homogeneização permite sugerir que houve significativo resfriamento e/ ou mistura de fluidos de diferentes composições após a fase mineralizante principal. A presença de $\mathrm{CaCl}_{2}$ nos fluidos secundários é interpretada como resultante de interação dos fluidos hidrotermais ricos em $\mathrm{Ca}$ com as rochas encaixantes reativas, resultante em paragêneses hidrotermais com carbonato.

Os fluidos aquocarbônicos e aquosos primários foram, certamente, os responsáveis pelo transporte e deposição do ouro. Fluidos tardios de baixa temperatura de homogeneização total e salinidade variável sugerem mistura de fluidos de diferentes composições e interação com as rochas encaixantes. Os veios de quartzo auríferos encaixados em granito na ocorrência Santo Elias foram originados por fluidos aquo-carbônicos e aquosos com elevada temperatura mínima de aprisionamento, baixa densidade e salinidade de até $27 \%$ em peso de $\mathrm{NaCl}$ eq., coerente com fluido gerado por devolatização metamórfica, possivelmente com contribuição granítica na sua composição.

CONSIDERAÇÕES FINAIS A distribuição regional das ocorrências de ouro do TGGT é controlada por zonas de cisalhamento brasilianas ou reativadas no Brasiliano (Araujo Filho \& Kuyumjian 1996). Tais ocorrências/depósitos ocorrem na forma de disseminações e veios de quartzo, em anfibolito rico em ferro, formação ferrífera bandada e granito submetidos à alteração hidrotermal sob condições compatíveis com a fácies xisto verde. Rochas ricas em ferro favorecem a remoção do enxofre durante sulfetação e a redução e precipitação do ouro (Phillips \& Groves 1984, Roberts 1987).

Em anfibolito e formação ferrífera do TGGT, veios de quartzo auríferos e xistos imediatamente encaixantes são enriquecidos em $\mathrm{Au}, \mathrm{As}, \mathrm{Ag}, \mathrm{Pb}, \mathrm{Cu}, \mathrm{Zn}$, $\mathrm{Ni}$ e Bi, sendo que as concentrações mais elevadas em $\mathrm{W}, \mathrm{Mo}, \mathrm{Nb}$ e Sr, na ocorrência Santo Elias, podem ser consequência de contaminação do fluido mineralizador ao percolar o biotita granito hospedeiro. As ocorrências de ouro do TGGT apresentam altas razões Au/Ag e baixas concentrações de metais básicos e, segundo Groves et al. (2000), estas são características de depósitos do tipo orogênico.

Idades e assinaturas geoquímicas de anfibolitos e tonalitos-dioritos do TGGT indicam subducção de litosfera oceânica em ambiente de arco continental na margem oeste do Cráton São Francisco durante o Paleoproterozoico. Adotando-se modelos de Groves 
et al.(1998) e Goldfarb et al. (2005) para a formação de depósitos orogênicos de ouro, fluidos hidrotermais resultantes de devolatilização metamórfica em níveis crustais mais profundos migraram para zonas de cisalhamento transcrustais no TGGT durante a orogênese Brasiliana, enriqueceram-se em ouro e, após o pico do metamorfismo, participaram de mineralização de ouro nas fases finais da deformação e estruturação da faixa Brasília na borda oeste do Cráton São Francisco (Cruz \& Kuyumjian 1993, 2006). Não há dados ou evidências que indiquem que as ocorrências de ouro do TGGT tenham resultado de mobilização e concentração, ou remobilização e reconcentração metamórfica de ouro singenético paleoproterozoico durante o Neoproterozoico.

Os principais parâmetros para exploração mineral objetivando depósitos de ouro no TGGT são: 1) supracrustais deformadas, submetidas à alteração hidrotermal e metamorfisadas na fácies xisto verde no âmbito de zonas de cisalhamento $\mathrm{NS}, \mathrm{N} 40-65^{\circ} \mathrm{E}$ e $\mathrm{N} 35-50^{\circ} \mathrm{W}$; 2) a maioria das ocorrências de ouro e anomalias de ouro em sedimentos de drenagem no TGGT localizam-se numa faixa de $80 \mathrm{~km}$ de extensão na direção $\approx \mathrm{N} 10$ $-20^{\circ} \mathrm{E}$, de Almas-Porto Alegre do Tocantins à Conceição do Tocantins, contendo falhas, faixas de greenstone e intrusões graníticas e máfico-ultramáficas; 3) contatos tectônicos entre domos e faixas de greenstone e junções de zonas de cisalhamento com padrão em Y controlam várias ocorrências de ouro; 4) xisto carbonoso, anfibolito rico em ferro e formação ferrífera bandada constituíram importantes armadilhas geoquímicas para a precipitação de ouro; 5) contacto entre formação ferrífera bandada e xistos favoreceu o fluxo de fluido hidrotermal e a precipitação de sulfetos e ouro; 6) veios de quartzo de um modo geral e zonas axiais de mesodobras em formação ferrífera e xistos encaixantes constituem alvos importantes; 7) quando quartzo leitoso e enfumaçado ocorrem em um mesmo veio, o segundo contém concentrações mais elevadas em ouro; 8) $\mathrm{As}, \mathrm{Ag}, \mathrm{Pb}$, $\mathrm{Cu}, \mathrm{Zn}, \mathrm{Ni}, \mathrm{Bi}, \mathrm{W}, \mathrm{Mo}$ e $\mathrm{Nb}$ constituem elementos farejadores para ouro; e 9) prospecção em sedimentos de drenagem, sensoriamento remoto multiespectral, magnetometria, gamaespectrometria e polarização induzida têm sido utilizados com sucesso para a identificação de alvos anômalos no TGGT, onde coberturas laterítica e de solos são extensas.

Agradecimentos Ao CNPq pelo apoio nas formas de bolsas de estudo a pós-graduandos e graduandos e auxílios à pesquisa (Edital Universal) para a realização desta pesquisa. Os autores agradecem aos revisores pelas críticas e sugestões.

\section{Referências}

Alvarez M.C.A. 2007. Mineralização de ouro do terreno Almas-Dianópolis, TO: guias de exploração mineral. Dissertação de Mestrado, Instituto de Geociências, Universidade de Brasília, Brasília, 78 p.

Araújo Filho J.O. \& Kuyumjian R.M. 1996. Regional distribution and structural control of gold occurrences and deposits in the Goiás Massif and Brasília Belt. Rev. Bras. Geoc., 26(2):109-112.

Araújo Filho J.O. \& Kuyumjian R.M. 2000. Structurallycontrolled gold occurrences in the southern Brasília fold-thrust belt of central and southeastern Goiás. Rev. Bras. Geoc., 30(2):289-292.

Arthaud M.M. 1988. Projeto Conceição do Norte. Goiânia, Metais de Goiás, Relatório Interno, 32 p.

Beard J.S. 1986. Characteristic mineralogy of arc-related cumulate gabbros: implications for the tectonic setting of gabbroic plutons and for andesite genesis. Geology, 14:948-951.

Bodnar R.J. 1993. Revised equation and table for determining the freezing point depression of $\mathrm{H}_{2} \mathrm{O}-\mathrm{NaCl}$ solutions. Geochimica Cosmochimica Acta, 57:683-684.

Borges M.S. 1993. Evolução tectono-estrutural da região de Dianópolis-Almas, SE do Estado do Tocantins. Tese de Doutorado, Instituto de Geociências, Universidade Federal do Pará, Belém, 365 p.

Brown P.E. \& Lamb W.M. 1986. Mixing of $\mathrm{H}_{2} \mathrm{O}-\mathrm{CO}_{2}$ in fluid inclusions: geobarometry and Archean gold deposits.
Geochimica Cosmochimica Acta, 50:847-852.

Correia Filho F.C.L. \& Sá A.M. 1980. Projeto Natividade. Goiânia, DNPM/CPRM, Relatório técnico, 120 p.

Costa J.B.S. 1984. Aspectos lito-estruturais e evolução crustal da região centro-norte de Goiás. Tese de Doutorado, Instituto de Geociências, Universidade Federal do Pará, Belém, 210 p.

Costa L.A.M., Nilson A.A., Vale C.R.O., Marchetto C.L.M., Santos E.L., Meneguesso G., Inda H.A.V., Sterna L.H., Marchetto M., Baptista M.P., Fratin O., Mosmman O., Oliveira T.F., Silva W.G. 1976. Projeto Leste Tocantins/ Oeste do São Francisco. Rio de Janeiro, DNPM/CPRM/ PROSPEC, Relatório final, $200 \mathrm{p}$.

Crawford M.L. 1981. Phase equilibria in aqueous fluid inclusions. Mineralogical Association of Canada Short Course, 6:75-100.

Cruz E.L.C.C. 1993. Geologia e mineralizações auriferas do Terreno Granitoide-Greenstone de AlmasDianópolis, Tocantins. Dissertação de Mestrado, Instituto de Geociências, Universidade de Brasília, Brasília, 152 p.

Cruz E.L.C.C. 2001. A gênese e o contexto tectônico da mina Córrego Paiol: um depósito de ouro hospedado em anfibolito do embasamento da Faixa de Dobramentos Brasília. Tese Doutorado, Instituto de Geociências, Universidade Brasília, Brasília., 183 p.

Cruz E.L.C.C. \& Kuyumjian R.M. 1993. O embasamento da porção norte da Faixa Brasília na região de 
Almas-Dianópolis (TO) e seu contexto geodinâmico durante o Brasiliano. In: SBG, Simpósio Cráton São Francisco, 2, Anais, p. 302-304.

Cruz E.L.C.C. \& Kuyumjian R.M. 1996. Chemical characterization of metabasalts and granitoids from the Almas-Dianópolis granite-greenstone terrane, central Brazil. In: SBG, Symposium Archaean Terranes South American Platform, 1, Extended Abstracts, p. 53-54.

Cruz E.L.C.C. \& Kuyumjiam R.M. 1998. The geology and tectonic evolution of the Tocantins granite-greenstone terrane: Almas-Dianópolis region, Tocantins State, Central Brasil. Rev. Bras. Geoc., 28(2):173-182.

Cruz E.L.C.C. \& Kuyumjiam R.M. 1999. Mineralizações auríferas filoneanas do terreno granito-greenstone do Tocantins. Rev. Bras. Geoc., 29(3):291-298.

Cruz E.L.C.C. \& Kuyumjian R.M. 2006. Geochronology, isotopic signature and metallogenetic model for the Córrego Paiol gold deposit, Tocantins state, central Brazil. Rev. Bras. Geoc., 36(1-Suplemento):152-156.

Cruz E.L.C.C. Kuyumjian R.M. \& Boaventura G.R. 2003. Low-K calc-alkaline granitic series of southeastern Tocantins State: Chemical evidence for two sources for the granite-gneissic complexes in the Paleoproterozoic Almas-Dianópolis Terrane. Rev. Bras. Geoc., 33(2):125-136.

Dardenne M.A., Giustina M.E.S.D., Sabóia A.M., Bogossian J. 2009. Datação geocronológica U-Pb da sequência vulcânica de Almas, Tocantins. In: SBG, Simp. Geol. Centro-Oeste, 11, Anais, 1 CD-Rom.

Dávila C.A.R. \& Kuyumjian R.M. 2005. Mineralizações de ouro do tipo orogênico em arco magmático paleoproterozóico, borda oeste do Cráton São Francisco, regiões de São Domingos (GO) e Correntina (BA). Rev. Bras. Geoc., 35(2):187-198.

Davis D.W., Lowenstein T.K., Spencer R.J. 1990. Melting behavior of fluid inclusions in laboratory-grown halite crystals in the systems $\mathrm{NaCl}-\mathrm{H}_{2} \mathrm{O}, \mathrm{NaCl}-\mathrm{KCl}-\mathrm{H}_{2} \mathrm{O}$, $\mathrm{NaCl}-\mathrm{MgCl}_{2}-\mathrm{H}_{2} \mathrm{O}$, and $\mathrm{NaCl}-\mathrm{CaCl}_{2}-\mathrm{H}_{2} \mathrm{O}$. Geoch. Cosmoch. Acta, 54:591-601.

Diamond L.W. 1992. Stability of $\mathrm{CO}_{2}$ clathrate hydrate + $\mathrm{CO}_{2}$ liquid $+\mathrm{CO}_{2}$ vapor + aqueous $\mathrm{KCl}-\mathrm{NaCl}$ solutions: experimental determination and application to salinity estimates of fluid inclusions. Geochimica Cosmochimica Acta, 56:273-280.

DOCEGEO 1995. Avaliação geoestatística da mineralização aurífera superficial da jazida do Paiol, Almas, TO. Palmas, DOCEGEO, Relatório Interno.

Ferrari M.A., Choudhuri A., Costa A.P. 1998. Estudo de zonas de alteração hidrotermal do greenstone belt de Almas-Dianópolis (TO) através de sensoriamento remoto multiespectral. In: Congresso Brasileiro de Geologia, 40, Boletim de Resumos, p. 329-329.

Ferrari M.A.D. \& Choudhuri A. 2000. Chemical and structural constraints on the Paiol Gold deposit, Almas greenstone belt, Brazil. Rev. Bras. Geoc., 30(3):297-301.

Ferrari M.A.D. \& Choudhury A. 2004. Structural controls on gold mineralisation and the nature of related fluids of the Paiol gold deposit, Almas greenstone belt, Brazil. Ore Geology Review, 24:173-197.

Fuck R.A., Dantas E.L., Botelho N.F., Oliveira C.G., Dardenne
M.A., Pimentel M.M. 2010. O Paleoprroterozóico na Província Tocantins. In: SBG, Congresso Brasileiro de Geologia, 45, Anais, 1 CD-Rom.

Goldfarb R.J., Baker T., Dube B., Groves D.I., Hart C.J.R., Gosselin P. 2005. Distribution, character and genesis of gold deposits in metamorphic terranes. In: Hedenquist J.W., Thompson J.F.H., Goldfarb R.J., Richards J.P. (eds.) Economic Geology 100 th Anniversary Volume. Littleton, Society of Economic Geologists, p. 407-450.

Goldstein R.H. \& Reynolds T.J. 1994. Systematics of fluid inclusions in diagenetic minerals. Tulsa, Society for Sedimentary Geology, Short Course 31, 199 p.

Gorayeb P.S.S., Costa J.B.S., Lemos L.R., Gama Junior T., Bemerguy R.L., Hasui Y. 1988. O Pré-cambriano da região de Natividade, TO. Rev. Bras. Geoc., 18(4):391-397.

Graf J.L. 1978. Rare earth elements, iron formations and sea water. Geoch. Cosmoch. Acta, 42:1845-1850.

Groves D.I., Goldfarb R.J., Gebre-Mariam M., Hagmann S.G., Robert F. 1998. Orogenic gold deposit: a proposed classification in the context of their crustal distribution and relationship to other gold deposit types. Ore Geology Reviews, 13:7-27.

Groves D.I., Goldfard R.J., Knox-Robinson C.M., Ojala J., Gardol S., Yun G.Y., Holyland P. 2000. Late-kinematic timing of orogenic gold deposits and significance for computer-base exploration techniques with emphasis on the Yilgarn Block, Western Australia. Ore Geology Reviews, 17(1-2):1-38.

Kuyumjian R.M. \& Araújo Filho J.O. 2005. Depósitos e ocorrências de ouro no terreno arqueanopaleoproterozóico de Almas-Dianópolis (TO): evidências da importância metalogenética do evento Brasiliano. Rev. Bras. Geoc., 35(4):611-614.

Kwitko R., Masotti F., Baars F.J., Abreu F.R., Bella V.C.M., Ferrari A.J.D., Fuck R.F., Gomes R.P., Ribeiro E., Tallarico F., Vial D.S., Viana F.H. 1995. Petrografia, alteração hidrotermal e mineralização aurífera da jazida do Córrego Paiol - Almas (TO). In: SBG, Congr. Bras. Geoquímica, 5, Anais, 1 CD-Rom.

Lima T.M. 2000. CPRM-Serviço Geológico do Brasil, Informe de Recursos Minerais 14, Projeto Platina GO/TO.

Nilson A.A. \& Valle C.R.O. 1973. Mapa Geológico da Folha SC.23-Y-C (Dianópolis) - Projeto Leste Tocantins/Oeste do São Francisco. Rio de Janeiro, DNPM/CPRM/ PROSPEC, mapa geológico, escala 1:250.000.

Oakes C.S., Bodnar R.J., Simonson J.M. 1990. The system $\mathrm{NaCl}-\mathrm{CaCl}_{2}-\mathrm{H}_{2} \mathrm{O}$ : I. The ice liquidus at 1 atm total pressure. Geoch. Cosmoch. Acta, 54:603-610.

Padilha J.L. 1984. Prospecção de ouro na região nordeste de Goiás-Projeto Pindorama-Docegeo. In: SBG,

Encontro Regional do Ouro de Goiás, I, Resumos, p. 78-95.

Phillips G.N. \& Groves D.I. 1984. Fluid access and fluid wall-rock interaction in the genesis of the Archean goldquartz vein deposit at Hunt Mine, Kambalda, Western Australia. In: Foster R.P. (ed.) Gold '82: the Geology, Geochemistry and Genesis of Gold Deposits (Geological Society of Zimbabwe special publications). Oxfordshire, Taylor \& Francis, p. 389-416.

Roberts R.G. 1987. Ore deposit model, Number 11: Archean 
lode gold deposits. Geocience Canadá, 14:37-52.

Shepherd T.J., Rankin A.H, Alderton D.H.M. 1985. A Practical Guide to Fluid Inclusion Studies. New York, Blackie and Son, $239 \mathrm{p}$.

Silva A., Souza L.H., Ferreira M.C.B. 1990. Alteração hidrotermal da sequência de rochas do alvo Córrego do Paiol e mineralização aurífera associada. In: SBG, Congresso Brasileiro de Geologia, 36, Anais, p. 1129-1143.

Teixeira A.S., Serradourada H.P., Souza L.H., Mattos S.C. 1986. Projeto Dianópolis - Relatório da Etapa III. Palmas, DOCEGEO-METAGO, Relatório Técnico, 33 p. Thompson R.N., Morrison M.A., Hendry G.L., Parry S.J. 1984. An assessment of the relative roles of crust and mantle in the magma genesis: an elemental approach. Phil. Trans. R. Soc. Lond., A310:549-590.

Thomsen F.P.R. \& Kuyumjian R.M. 1994a. As formações ferríferas bandadas da região de Conceição do Tocantins, TO: caracterização preliminar. In: SBG, Congr. Geol. Centro-Oeste, 4, Resumos, p. 72-73.

Thomsen F.P.R. \& Kuyumjian R.M. 1994b. Caracterização geoquímica preliminar das rochas granitóides da região de Conceição, TO. In: SBG, Congr. Geol. Centro-Oeste, 4, Goiânia, Resumos, p. 26-27.

Zhang Y.G. \& Frantz J.D. 1987. Determination of the homogenization temperatures and densities of supercritical fluids in the system $\mathrm{NaCl}-\mathrm{KCl}-\mathrm{CaCl}_{2}-\mathrm{H}_{2} \mathrm{O}$ using synthetic fluid inclusions. Chemical Geology, 64:335-350.

Manuscrito ID 22768

Submetido em 26 de agosto de 2011 Aceito em 07 de fevereiro de 2012 